Vol. 68, N. ${ }^{\circ}$ 108 (noviembre 20I6), 97-I26

\title{
HACIA UNA «MONEDA ELECTRÓNICA PARALELA» PARA AFRONTAR LA CRISIS ¿POR QUÉ Y CÓMO HACERLO?
}

\author{
JÜRGEN SCHULDT ${ }^{\mathrm{I}}$, ALBERTO ACOSTA ${ }^{2}$ \\ ${ }^{1}$ Universidad del Pacífico (Perú), ${ }^{2}$ Investigador independiente
}

Recepción manuscrito: 23 de septiembre de 2016

Aceptación versión final: 31 de octubre de 2016

\begin{abstract}
RESUMEN Este artículo propone implementar un bimonetarismo en el Ecuador para afrontar la crisis vivida por el país especialmente desde 2015. En resumen, se propone pagar inicialmente 10 por ciento de las remuneraciones del sector público en dólares ecuatorianos (EC\$), los cuales serían emitidos en dinero electrónico, con posible emisión física futura. Los tenedores de EC\$ tendrían un descuento de cuatro puntos porcentuales en el impuesto al valor agregado (IVA) al comprar mercancías junto con otros beneficios, y podrían devolverlos al gobierno al pagar impuestos, pero dos años después de ser emitidos. Si los EC $\$$ no se usan después de esos dos años, «caducan» - pierden valor-. El artículo describe las diferentes etapas en que esta propuesta se desarrollaría, así como algunas de sus potenciales implicaciones. PALABRAS CLAVE Dólar ecuatoriano, bimonetarismo, dinero electrónico, política monetaria.
\end{abstract}

ABSTRACT This article proposes to implement a two-currency system - bimonetarism - in Ecuador in order to face the crisis suffered in our country, especially since 2015. Briefly, it proposes to initially pay 10 percent of the public remunerations with Ecuadorian dollars (EC\$), which would be issued as electronic money, with likely future physical issue. EC $\$$ holders would have a discount consisting of four percent points in the IVA plus further benefits when buying goods, and they could return them to the government upon paying their taxes, only after two years after they had been issued. If EC $\$$ are not used after those two years, they «expire» - lose their value-. This paper describes the different stages how this proposal would develop, as well as some of its potential consequences.

KEYWORDS Ecuadorian dollar, two-currency system (bimonetarism), electronic money, monetary policy.

JEL CODES E42, E52, H12, O23.

\section{INTRODUCCIÓN}

En el Ecuador, con su economía atrapada por la rigidez de una dolarización oficial o de jure, no existen reales debates dirigidos a recuperar los espacios de manejo monetario y cambiario 
indispensables para relanzar y fortalecer su alicaído y dependiente aparato productivo. Si la dolarización se impuso ${ }^{1}$ enarbolando el discurso de la inexistencia de alternativas ${ }^{2}$ y de las amenazas de una debacle económica, ${ }^{3}$ ahora se la protege con mensajes inspirados en los mismos temores y miedos. Incluso las discusiones sobre «dinero electrónico» - a las que volveremos en su momento- que intenta introducir el gobierno, están sobrecargadas de apreciaciones subjetivas y de epítetos, antes que de reflexiones serias ${ }^{4} \mathrm{o}$ argumentos sólidos. En realidad, tras bambalinas, se oculta un hecho concreto muy simple: paradójicamente la dolarización, aun cuando el Ecuador perdió al sucre como moneda de curso legal, no suprimió la influencia monetaria estatal. Es así que del control de la moneda por parte del Estado ecuatoriano se pasó al control del Estado norteamericano, a través de la Reserva Federal (FED). De ahí que no deba sorprender que la gran mayoría de países en el planeta tenga soberanía monetaria y cambiaria, no habiéndosela cedido a un poder foráneo a pesar de las tentaciones de propuestas «dolarizadoras», ${ }^{5}$ que a inicios de los años 1990 y 2000 estuvieron muy presentes en América Latina. ${ }^{6}$

Basta evaluar los resultados de la dolarización, más allá de la propaganda, para detectar sus limitaciones. En Ecuador, la inflación de un dígito, en casi diecisiete años de dolarización, no entusiasma desbocadamente, ya que aún sigue siendo notablemente mayor a la de EE. UU. La calma conseguida por la ausencia de devaluación no se refleja en una caída sustantiva de las tasas de interés; la activa es superior a las tasas, también en dólares, en varios países vecinos - Colombia, Perú, Bolivia, Costa Rica - que no se han dolarizado de jure. ${ }^{7}$ La dolarización oficial tampoco garantiza el equilibrio fiscal, como se ofreció cuando se la impuso. La recuperación económica, basada en la bonanza petrolera de inicios de este siglo - aunque con tasas de crecimiento inferiores a aquellas del anterior auge petrolero de los años setenta del siglo pasado-, pudo haber sido incluso mucho más importante sin dolarización, es decir, si se contaba con un adecuado manejo monetario y cambiario; eso incluso pudo haber ayudado a cristalizar la transformación de la matriz productiva, que hasta ahora solo es un simple discurso oficial, sin avances sustantivos y, en algunos casos, hasta con retrocesos. La dolarización se sostuvo en estos años porque los dólares abundaban: remesas de emigrantes, elevados precios del petróleo, acceso a créditos externos, entre otros flujos financieros, incluido un importante volumen de dólares del narcotráfico. Igualmente, y esto no es menor, la depreciación del dólar estadounidense permitió sostener la competitividad — si bien espuria - de las exportaciones ecuatorianas.

En los recientes años de bonanza petrolera se llegó inclusive a hablar del «milagro ecuatoriano». Pero cuando cae el precio del crudo, se aprecia el dólar estadounidense y se devalúan las monedas de nuestros vecinos, afloraron las endebles costuras de la economía ecuatoriana, cuya situación crítica estaba larvada desde antes. Una lectura de esta evolución y de las causas de la actual crisis económica — que se abordan detalladamente en Acosta y Cajas Guijarro (2015 y 2016a) - es fundamental para entender el significado de la dolarización oficial para la economía ecuatoriana; ésta ha ahondado, entre muchos otros factores, los desniveles de competitividad sistémica estructural de la economía, ante la ausencia de un manejo cambiario y monetario soberano, que distorsiona la estructura de los precios relativos y lastra la política fiscal.

En ese contexto económico y sociopolítico surge nuestra propuesta. Se trata de la introducción de una moneda paralela al dólar estadounidense: el dólar ecuatoriano. Como consecuencia 
de la adopción de esa medida la actual dolarización de jure, se convertirá en una de facto. Con lo que ambas monedas competirán entre sí, tal como sucedió y sigue dándose en países con elevada dolarización de los depósitos y los créditos del sistema financiero. Esto se ha registrado en aquellas economías latinoamericanas que experimentaron un proceso pre o propiamente hiperinflacionario y en las que el dólar estadounidense sigue jugando un papel determinante, tanto así que aún no permite el manejo de una política monetaria plenamente soberana.

Es indispensable entender que destrabar la trampa cambiaria no puede ser, de ninguna manera, el gran objetivo del manejo económico. Recuérdese que la política monetaria y cambiaria es apenas un medio, no un fin. Esto demanda diseñar una propuesta con costos relativamente controlados y equitativamente distribuidos, que debe contar con los consensos políticos necesarios. Y, por cierto, debe resultar de una acción planificada a partir de una estrategia adecuada, la cual incluso tome en cuenta la transformación de la producción del país reduciendo su dependencia a la importación de medios de producción y, con eso, disminuya la presión monetaria generada por la «salida estructural» de dólares en tales importaciones. Más importante: la recuperación del manejo cambiario-monetario tampoco basta si no pensamos en una necesaria concepción de políticas y cambios estructurales alternativos para Ecuador. Una concepción que atienda las demandas básicas del ser humano, viviendo en armonía con la naturaleza, en contraste con las exigencias ciegas de acumulación del capital como eje económico.

Éstas, en última instancia, son visiones que propugnan las políticas neoliberales, cuyo éxito se evalúa, por ejemplo, en base a los índices de riesgo país para determinar la rentabilidad -o sea el grado de sumisión - frente a los acreedores de la deuda externa. Cuando de lo que se trata es poner la mira en el bienestar de la población, que es lo que nosotros proponemos y avizoramos para el país en el largo plazo, sobre la base de esquemas a escala del desarrollo humano (Schuldt, 2013) o en términos del Buen Vivir en tanto alternativa al desarrollo (Acosta, 2013b). Para entrar en materia, cabrá preguntarse ¿cómo introducir una moneda nacional, que conviva con el dólar, y cómo hacerlo sin provocar una descapitalización de la economía? He aquí el reto fundamental.

\section{GENERALIDADES DE LA PROPUESTA}

Las revoluciones tecnológicas de las últimas décadas han permitido avances espectaculares en la ciencia y la economía, entre otros. Dos de ellas, celulares y dinero electrónico, nos servirán como instrumentos para proponer un esquema monetario complementario al sistema existente en el país, para hacerlo más eficiente y, sobre todo, para liberar la gestión económica de la camisa de fuerza que significa la dolarización de jure vigente desde enero de 2000. Con ello se recuperaría la posibilidad de adoptar políticas relativamente soberanas en los campos monetario-financiero y cambiario.

La grave - y aún parcialmente enmascarada - crisis económica y sociopolítica que, más temprano que tarde, se agudizará en el Ecuador, nos impulsa a presentar una propuesta económico-política heterodoxa, centrada en introducir paulatinamente un medio de cambio complementario al dólar estadounidense por parte del gobierno. Como tal, se trata de establecer un sistema monetario paralelo que introduciría otro dinero: el dólar ecuatoriano. ${ }^{8}$ Éste sería 
complementario y entraría en competencia con el dólar norteamericano, que seguirá existiendo de facto. ${ }^{9}$ Este proceso y sus resultados serán responsabilidad del gobierno y, particularmente, del Banco Central del Ecuador (BCE) según las pautas que detallaremos a continuación.

A primera vista, la propuesta parecerá compleja, no solo por los peculiares mecanismos de funcionamiento a que dará lugar, sino en especial por las precondiciones institucionales que requiere su aplicación adecuada. Incluso esto implicaría adoptar reformas a la resolución $n$. ${ }^{\circ}$ 274-2016-M de la Junta de Política Monetaria y Financiera. Pero así como es indispensable identificar las potenciales dificultades que ocasione la introducción de este sistema bimonetario, se deben resaltar las promesas que derivarían de su aplicación para la población: menores costos de transacción monetaria, creciente formalización e inclusión financiera, menor carga tributaria indirecta y su contribución a la reactivación económica, gracias también a menores tasas de interés resultantes de la mayor liquidez que ofrecería la introducción del dinero paralelo. ${ }^{10}$

La emisión monetaria es una facultad del Estado que potencialmente contribuye a fortalecer el crecimiento económico y que debería facilitar la construcción de otra economía. Por eso, hay que recuperarla y preservarla como herramienta que permite actuar con flexibilidad ante las cambiantes situaciones de la economía mundial. Y esta facultad será aceptada socialmente en el marco de una política monetaria no arbitraria, pues solo la confianza en ella contribuirá al bienestar de la sociedad. Si bien construir confianza exigirá algunos requisitos tangibles como adecuadas políticas económicas, lo que sí debe estar claro es que, en definitiva, se requiere construir un sistema de pagos confiable y dinámico, y de relaciones comerciales consistentes. Se trata de establecer condiciones relativamente predecibles y manejables. Por cierto, de la experiencia ecuatoriana habrá que extraer lecciones que deberían cristalizarse en una política económica que no abra la puerta a salvatajes bancarios, sucretizaciones (Acosta 1994) o macrodevaluaciones, tan comunes en la época neoliberal (Acosta 2012). Eso sí, el manejo de la liquidez en una economía, es decir, el flujo ágil e inmediato de dinero es fundamental, pues a mayor movilidad del mismo mayor será el dinamismo en la economía y menores los costos de transacción.

El proceso será complejo y de múltiples repercusiones, sin espacio para improvisar. Los tiempos y contenidos estarán determinados por las fuerzas políticas que lideren dicho sistema, el que requiere cuanto mercado y regulación sean necesarios. No es recomendable tomar medidas por sorpresa, pues eso debilitará la adopción posterior de nuevas medidas cuando sean necesarias. Luego de analizar los riesgos y las ventajas para impulsar un proceso ordenado, procurando identificar los posibles grupos afectados y los beneficiarios, hay que desarrollar las capacidades necesarias para ajustar sobre la marcha la propuesta a partir de las cambiantes condiciones sociopolíticas internas y económicas externas. Pero que quede absolutamente claro que no se propone recuperar la emisión para financiar déficits fiscales o para un nuevo salvataje bancario o para que grupos de exportadores se beneficien permanentemente con devaluaciones del tipo de cambio, que solo dan lugar a incrementos espurios de la competitividad. Para evitar estas indeseables situaciones, tampoco se puede sostener la rigidez cambiaria, que también es problemática. Un punto importante: en el Ecuador, a diferencia de Argentina con la convertibilidad, para recuperar espacios soberanos de política monetaria y cambiaria, hay que introducir una moneda paralela; tema que desarrollamos esquemáticamente a continuación. 


\section{EL DINERO ELECTRÓNICO COMO MEDIO \\ DE CAMBIO NACIONAL PARALELO AL DE USO OFICIAL}

¿Qué entenderemos como «medios de pago paralelos» o «dineros complementarios»? En la literatura reciente se asume - generalmente de forma implícita- que el carácter paralelo o complementario es evidente, cuando en la práctica son múltiples sus acepciones. ${ }^{11}$ Frente a esa ambigüedad, precisaremos la definición específica siguiendo a diversos autores especializados en el tema y en los que nos hemos basado en buena medida en este artículo. Si bien el debate académico sobre monedas paralelas es relativamente reciente, es posible distinguir dos tipos de medios de cambio «paralelos» $\mathrm{o}$ "complementarios»: los impulsados «desde abajo» $\mathrm{y}$ los que se dictan «desde arriba».

Los primeros surgieron desde bases locales, consensuados democráticamente y abarcando un territorio subnacional -regional, provincial, distrital o comunitario-, inicialmente creados en varios lugares de Europa como consecuencia de las crisis de los años veinte y treinta, pero que se han expandido - y siguen haciéndolo hasta hoy- a muchos otros territorios del planeta. La literatura al respecto es enorme, por lo que nos limitaremos a nombrar unos pocos textos que explican esas experiencias muy heterogéneas y que contienen una vasta bibliografía para los interesados: Greco (1994), Schuldt (1997), Kennedy, Lietaer y Rogers (2012) y Rogers (2013). El otro enfoque de dineros paralelos, que es el que aquí nos interesará, ${ }^{12}$ abarca la escala macroeconómica-nacional y sería impulsada y administrada por el gobierno. Hasta hoy, este planteamiento no se ha practicado, limitándose a lo estrictamente teórico-tecno-político. Este enfoque, así como el debate consecuente, surgió luego de la gran recesión estadounidense (2007-2008) que contribuyó a desencadenar las crisis de varias economías, especialmente de aquellas de la eurozona mediterránea.

De ahí que los diseños de una moneda paralela, por ejemplo, al euro, han ido desarrollándose - especialmente desde 2010 y pensando particularmente en Grecia- por economistas académicos, generalmente poskeynesianos o marxistas. En nuestra opinión, los más destacados autores - a pesar de sus diferencias - son Andresen y Parenteau (2015a y 2015b), Harvey (2015), Hilliger (2015), Hozawa y Torrens (2015a y 2015b), Litaer (2012 y 2015), Mayer (2015a y 2015b), Sapir (2015) y Varoufakis ${ }^{13}$ (2013, 2014 y 2015), entre otros muchos. Sus desafiantes e innovadores trabajos se refieren a las monedas paralelas para economías atadas de jure a la moneda nacional suprarregional como es el euro $-\mathrm{y}$ en menor medida a una foránea, como el dólar norteamericano- y sometidas a graves problemas de liquidez. Para esto, proponen una nueva moneda complementaria - llamada greco o greuro para el caso de Grecia- a la de curso legal -el euro- como medio de cambio para recuperar, siquiera parcialmente, su soberanía monetaria. Es en este enfoque - a escala nacional y promocionado por el gobiernoen el que nos hemos inspirado, en parte, para elaborar la presente propuesta.

La aplicación de un programa de este tipo habría podido ser adoptado en Grecia luego del triunfo electoral de Tsipras, quien asumió el premierato en enero 2015. ${ }^{14}$ En Ecuador, en cambio, el debate sobre una posible desdolarización ha sido marginal. ${ }^{15}$ Cabe notar que esta propuesta de «moneda paralela» sería la primera que se adoptaría a nivel nacional o macroeconómico - y a cargo del gobierno- en el mundo. Todas las anteriores, exitosas o fracasadas, 
se han adoptado a nivel subnacional; es decir, fueron aplicadas en espacios geográficos mucho más estrechos: pueblos, distritos, provincias o regiones. La segunda diferencia fundamental entre las monedas paralelas subnacionales o regionales vis a vis con la moneda paralela nacional que aquí propondremos es que, en este caso, es el gobierno el que inicia, lidera y supervisa el sistema. En cambio, las monedas que solo circulan en espacios subnacionales están a cargo de representantes del pueblo y de las comunidades. ${ }^{16}$ Aquí no nos ocuparemos de estas fascinantes micro $y$ mesoexperiencias, si bien las consideramos esenciales para fortalecer las economías locales que - al formar parte de la periferia nacional - son las que más sufren en períodos de crisis económica nacional. Lo que, sin embargo, no significa que las descartemos, sino todo lo contrario: nos parece válido que — complementando el dinero pararelo nacionalbien pueden seguir naciendo o expandiéndose los dineros «locales», como de hecho viene sucediendo y que - esperamos - algún próximo gobierno apoye de manera oficial y sistemática en el Ecuador, sin quitar la capacidad autonómica de estas propuestas. ${ }^{17}$

\section{ELEMENTOS SUSTANTIVOS DEL NUEVO SISTEMA MONETARIO}

En lo que sigue, explicaremos este peculiar paradigma monetario ${ }^{18}$ a grandes rasgos y en sus, cuando menos, cuatro fases de instrumentación: i) la preparatoria que implica resolver ex ante una serie de problemas políticos, legales y administrativos, estableciendo las precondiciones indispensables para el adecuado funcionamiento de esquema bimonetario; ii) la más delicada, en la que el gobierno - por intermedio del banco central - introducirá el dinero complementario - que no será de curso forzoso- al dólar estadounidense vigente de jure; iii) en la que se transita y desenvuelve en su proceso de maduración y auge; y iv) una vez resuelta la crisis fiscal y de reactivación económica, existirían dos vías alternativas, sea eliminando la «moneda complementaria» o dólar ecuatoriano, regresando plenamente al dólar norteamericano como moneda «oficial», o generalizando paulatinamente ese medio de cambio paralelo y convirtiendo al dólar ecuatoriano en la moneda oficial — de curso legal—, cancelando la dolarización de jure, aunque parte importante de la liquidez aún estaría dada en dólares norteamericanos, la que se iría reduciendo con el tiempo. Nos inclinamos por esta segunda opción y es la que desarrollaremos en lo que sigue.

A primera vista, parecerá difícil su concepción e instrumentación, frente a lo cual argumentaremos que esta vía nos ofrece la forma más realista para incrementar paulatinamente la escuálida liquidez de la economía ecuatoriana, a la vez que permitiría cuadrar las cuentas fiscales y reactivar gradual pero sostenidamente la economía. La reducción de la dolarización que ya no sería de jure sino de facto-probablemente se daría a lo largo de toda una década, durante la cual el dólar ecuatoriano se convertiría paulatinamente en un medio de cambio cada vez más aceptado por la población hasta convertirse en el dinero de curso forzoso, que podría darse por decisión de la Asamblea Nacional.

Como ilustración de ese proceso, pensemos en una lenta desdolarización, similar a aquella de las economías que sufrieron una etapa de hiperinflación en los años ochenta o noventa y que entonces sufrían una elevada dolarización de facto del 80 al 90\% de los depósitos y que, a lo largo de la década pasada — y hasta hoy— han logrado «nacionalizar» los depósitos, al 
alcanzar una dolarización de hecho del 30 al 40\%; Bolivia y Perú, por ejemplo. Así se recuperaría, en términos relativos, la autonomía relativa del вСE para adoptar políticas monetarias y cambiarias que hoy serían muy útiles para ayudar a evitar el descalabro económico y sociopolítico ad portas del país.

\section{LA FASE PREPARATORIA}

La etapa inicial de la emisión monetaria, a pesar de la emergencia, requiere de un buen tiempo para que las autoridades que propugnan introducir la moneda complementaria a la oficial se pongan de acuerdo sobre algunas interrogantes críticas y, especialmente, para afrontar aspectos cruciales que deben tratarse paralelamente, lo que permitiría que se refuercen entre sí. Estos aspectos se enumerarán brevemente aquí y se plantearán con más detalle en los apartados siguientes. Por cierto, un sistema de esta naturaleza solo se puede dar en un contexto de respeto a las instituciones, que garantice, en particular, la independencia de funciones del Estado Ejecutivo, Legislativo, Judicial, Electoral y Control-, al tiempo que se asegura el funcionamiento del banco central como lo establece la constitución. ${ }^{19}$

Proponemos que este sistema paralelo de monedas sea administrado por el BCE. Este banco controlará, evaluará y perfeccionará el «sistema monetario paralelo», bajo las funciones de control de la «emisión» del dinero paralelo, de monitoreo de las condiciones inflacionarias y del establecimiento de un sistema de alerta temprana frente a una potencial aceleración de la inflación, etc. El BCE tendrá que publicitar las características y beneficios del uso del dólar ecuatoriano y evaluar las diversas fórmulas de pago, sea por el preferencial sistema electrónico encriptado, sea por certificados o, propiamente, con monedas y billetes. Este último de los esquemas quizá no será necesario, pues prácticamente toda la población posee algún tipo de móvil para comunicarse y realizar las transacciones electrónicas necesarias con ambos dineros por mensaje simple de texto (sms, por sus siglas en inglés de Short Message Service). ${ }^{20}$

Antes de entrar en detalles, repetimos que el programa propuesto busca introducir el dólar ecuatoriano (EC\$), entendido como una cuasimoneda, y que, como tal, servirá de medio de cambio paralelo al dólar estadounidense (US\$), proceso que permitiría liberar recursos — dólares norteamericanos - para el fisco, paralelamente a lo cual se expandirá el potencial de gasto e inversión pública y del consumo de los agentes económicos privados, aumentando la demanda agregada y, con ello, generando una recuperación endógena de la economía. Más precisamente, de lo que se trata - en primera instancia - es de instrumentar un mecanismo adicional de financiamiento de la economía, no solo del gobierno. A la larga, ello recuperará en gran medida la soberanía monetaria del Ecuador, junto a una política cambiaria sustentada en el bimonetarismo. ${ }^{21}$

\section{EL PROCESO MÁS CRÍTICO: LA EMISIÓN MONETARIA PARALELA INICIAL}

Asumamos que se resolvieron los problemas mencionados y que se instalaron las instituciones e infraestructura para que funcione el sistema, por lo que podemos ir directamente a explicar la propuesta en su fase más delicada. Tratándose de una que aún no se ha aplicado a país alguno a escala nacional, los planteamientos siguen abiertos a discusión y perfeccionamiento. Sin embargo, existen países en donde se pueden abrir cuentas en varias monedas, con lo que ya existen respuestas al sistema planteado. 
Un primer asunto — quizá el más importante por discutir - es cómo se generaría el dinero paralelo. Sugerimos, siguiendo parcialmente la pauta de los varios autores mencionados, que ello se realice a partir de los sueldos de los empleados públicos. A ellos se les pagaría una parte menor de su remuneración mensual total en EC\$ y el resto en US\$. Esa porción inicialmente podría representar el 10\% de la remuneración de cada uno, la que se abonará en una cuenta electrónica de EC $\$$ en el banco central y el restante 90\% se le transferirá - como de costumbre- a través del sistema financiero, en us $\$ .{ }^{22}$ Más concretamente se trata de un proceso que incorporará el dinero electrónico — como medio de pago- a la economía nacional, no a través de instituciones financieras privadas, sino desde el gobierno, en particular, bajo responsabilidad del все. ${ }^{23}$ Así, ese dinero se establecería a escala nacional, sin intereses, ni costos, ni límites al monto de la transacción. Como tal se trata de una cuasimoneda - el dólar ecuatoriano- que circularía paralela al dinero de jure, el dólar norteamericano.

Téngase presente que en el Ecuador ya existe, a nuestro entender también un caso único a nivel mundial, la «billetera monetaria» - dinero electrónico- a cargo del Estado, aunque no ha tenido el éxito esperado. Éste no se debe confundir con la «billetera monetaria» a cargo de la banca o empresas privadas existente en varios países. Al margen de ello, en nuestra propuesta se utilizará precisamente la plataforma tecnológica del BCE para el efecto —o, eventualmente, de alguna nueva institución pública independiente- ${ }^{24}$ a la que se le añadirían algunos ajustes para crear en él una cuenta especial, que solo albergaría los depósitos de tales medios de pago electrónicos que poseerá la ciudadanía, a la que denominaremos la caja.

Este instrumento de transacción — no pensado como depósito de valor - se crearía por la generación de flujos monetarios en EC\$, depositados en la Cuenta del BCE, provenientes inicialmente - y por un lapso de tres a seis meses- de solo 10\% del 100\% de los depósitos mensuales del total de las remuneraciones de los empleados del gobierno. Luego, esta cuota en EC\$ se aumentará paulatinamente, como veremos. Se trata de sumas importantes las que entrarían en juego con la entrega - mes a mes - de US\$ y un valor adicional de EC\$, considerando que este incremento, cuando menos, abarcaría a medio millón de empleados públicos en Ecuador (INEC). De hecho, si se considera que al año se destinan alrededor de usD 9000 millones en sueldos de empleados del gobierno dentro del Presupuesto General del Estado, entonces esta medida podría implicar la inyección de, al menos, 900 millones de dólares ecuatorianos durante el primer año de emisión asumiendo que en el año se mantiene fijo el 10\% de remuneraciones en moneda paralela. En cambio, si en el primer semestre es $10 \%$ y en el segundo semestre se pasa a $20 \%$, se podría alcanzar una emisión aproximada de 1350 millones de dólares ecuatorianos.

Téngase en cuenta, además, que en promedio los empleados del sector público obtienen ingresos laborales que llegan a ser de casi el doble de aquellos que reciben los del sector privado. Por ejemplo, según datos del INEC, a junio de 2016, mientras que un empleado dependiente del gobierno - sea en la burocracia, en educación, en salud pública o en otras actividades dependientes del sector público - obtuvo un ingreso laboral promedio de USD 973 mensuales, un empleado privado recibió usD 487 mensuales. Esto da una idea del poder de compra adicional que se generaría con la emisión mensual de la moneda paralela, pero también la carga que debe sostener el sistema fiscal. 
Lo que interesa es que, desde un inicio, los empleados del Estado sepan que la entrega de parte de su remuneración en dinero paralelo no es propiamente una transferencia coercitiva de sus remuneraciones; ${ }^{25}$ inclusive se puede estructurar un esquema que entregue de forma diferenciada más EC\$ a aquellos funcionarios públicos que tengan las remuneraciones más altas hay que prever para que estos servidores no usen información privilegiada a fin de "especular» para obtener ganancias por medio del tipo de cambio entre el dólar ecuatoriano y el norteamericano- - Ellos deben estar convencidos de que con el dinero electrónico - como medio de pago paralelo al dólar norteamericano- poseerán la comodidad de comprar prácticamente todo lo que deseen. La disponibilidad de este dinero electrónico serviría inclusive para que los servidores públicos tengan mayor certeza respecto a su estabilidad laboral. Lo más importante, sin embargo, es que por el uso del dinero electrónico en la compra de bienes y servicios a todos los usuarios de dicho dinero se les otorgaría un descuento del IVA en 4 puntos porcentuales - bajando del actual 14\% al 10\%, como ya se practica ahora para quienes voluntariamente adquieren y utilizan una billetera electrónica en Ecuador-. Tal rebaja aplicaría por cada compra electrónica de bienes o servicios sujetos al IVA. ${ }^{26}$ Esta reducción es precisamente el «incentivo» que se les ofrece a los usuarios del dólar ecuatoriano por formar parte de - y aceptar- este sistema público de dinero electrónico paralelo.

A ese respecto es interesante notar que una buena parte de la canasta familiar básica paga IVA. Ese paquete de bienes y servicios que conforman el Índice de Precios al Consumidor (IPC) y que es la base para medir la inflación, está conformada por 359 productos que el INEC señala como más representativos en el gasto de los hogares: 208 pagan IVA — lo que es el 58\% de tales mercancías-, mientras que el restante 151 no lo exige. Ciertamente, quienes no deseen o no puedan utilizar los EC\$, podrían gastarlos - en parte o completamente- para el pago de sus impuestos, pero recién al cabo de dos años de emitido los EC\$. Aquí cabría analizar la forma en que se introduce este sistema para los gobiernos autónomos descentralizados, en donde, a los dos años, también se podría permitir el pago de impuestos prediales y patentes, por ejemplo, inclusive se podría alentar dicho pago con algún descuento, como sucede en la actualidad para quienes pagan en los primeros días de cada año.

Este principio - esperar dos años para el pago de impuestos- es esencial para que funcione el sistema, pues, de lo contrario, los tenedores de EC\$, al momento de que les sean acreditados a sus cuentas, los utilizarían para la cancelación inmediata de impuestos, tarifas y demás tributos y tasas del gobierno. Así no se lograría, a corto plazo, la necesaria expansión de la masa monetaria y el gobierno no podría incrementar su tenencia de us\$, que es precisamente lo que se puede lograr pagando parte de las remuneraciones en dinero complementario - EC\$—, con lo que se amplía la disponibilidad financiera estatal orientada a alentar la producción. Por cierto, hay otras opciones a considerar para fomentar el uso del dólar ecuatoriano; por ejemplo, se podría vender con descuento la electricidad, los combustibles o el mismo servicio telefónico, si se los cancela con EC\$. Igualmente cabe analizar la posibilidad de que en algún momento, cuando el sistema haya madurado, la banca pública ofrezca créditos preferenciales en EC\$, que incluso deberán tener un menor porcentaje de encaje bancario que los us\$ para la banca privada. El manejo de tasas de interés diferenciadas sería muy importante para alentar el uso de la moneda nacional, la que, incluso, podría subastarse colocándola con algún descuento para que 
aumente su atractivo. Un punto a favor es la disponibilidad de moneda nacional fraccionaria emitida por el Estado ecuatoriano, la cual no está ni puede estar denominada en us\$ y que ya cuenta con la confianza de la sociedad. A partir de ella se podría comenzar la emisión soberana de la nueva moneda nacional, ampliando el circulante existente e incluso acuñando monedas de mayor valor. ${ }^{27}$ El éxito del sistema radica en incorporar a otros segmentos de la población. Recordemos que el uso de sms como base de la plataforma es lo que permite que cualquier persona que utiliza la telefonía celular pueda «bancarizarse», llegando incluso a los lugares más recónditos del país; sin embargo, la plataforma tecnológica debe considerar diversas opciones, tanto para teléfonos inteligentes con internet como para teléfonos sin ese servicio; así como una versión en línea, principalmente para transacciones entre empresas y cuando los montos en cuestión son muy elevados. Aquí cabe considerar la necesidad de desarrollar una plataforma para intermediar y saldar facturas de toda la economía, tanto del sector público como del privado, con una suerte de cámara de compensación, como la existente en el sistema financiero. Esta contribuiría, además, a disminuir la necesidad de dólares circulantes y, por cierto, de financiamiento de corto plazo de las empresas. Además, este sistema de intercambio de facturas electrónicas, al ser su emisión controlada por el Servicio de Rentas Internas (SRI), contribuiría a reducir la evasión tributaria.

La idea, en definitiva, es alentar el uso del dólar ecuatoriano. Para lograrlo nada mejor que aumentar el costo de oportunidad y el costo del uso de los us $\$$ y reducir el de los EC\$. Esto se logrará no desde lógicas coercitivas, sino desde una confianza generalizada que deberá forjarse con políticas y acciones adecuadas. En algún momento se podrá estudiar la conveniencia de respaldar el dólar ecuatoriano con medidas legales. Si Ecuador experimentó en los años noventa del siglo pasado una dolarización espontánea ${ }^{28}$ vía intermediación financiera alentada por varias reformas jurídicas aprobadas sobre todo desde 1992, la recuperación de la moneda nacional también se debe procesar por el sendero de ajustes jurídicos; un asunto que por lo demás no reviste mayor dificultad si se asume el reto con responsabilidad.

Ciertamente que con ese sistema es el gobierno el que teóricamente reduce su gasto corriente efectivo, ahorrando US\$: en un inicio gastará un 10\% menos de dólares en remuneraciones. Esa liberación monetaria es esencial en el proceso económico que le seguirá, pues el gobierno lo podrá utilizar para fines de inversión pública, que reactivaría la economía sin necesariamente acelerar el alza general de precios, en presencia de una elevada capacidad ociosa de producción actual; a pesar de que, efectivamente, la masa monetaria aumentará por la generación del dinero paralelo, a la par que seguramente también lo hará su velocidad de circulación. Hay que considerar que cualquier efecto positivo de la inversión pública podría perderse si ésta no influye realmente en la producción. La experiencia reciente nos está mostrando que no basta con confiar en el efecto multiplicador del gasto público, sino que ese efecto debe traducirse en producción real -es decir, inversión en infraestructura industrial, manufacturera, agrícola-. Si la inversión pública es verdadera inversión, es decir, realmente sí contribuye a ampliar y diversificar la producción, entonces eso podría mitigar el alza de los precios. ${ }^{29}$ Pero, de nuevo, eso requiere que el gobierno realmente procese una inversión productiva que diversifique la producción para el mercado interno y el PIB potencial, con lo que tendrá que intervenir directa o indirectamente en la producción. 
Debe tenerse presente que el dólar ecuatoriano - cuando menos en los primeros años- no sería declarado aún como moneda de curso legal, sino solo como una especie de «certificado de adelanto de pago de impuestos» $\mathrm{O}$ «nota de tributación anticipada», como la ha denominado Parenteau (2014). Se trata de una «nota de tributación anticipada» pues el gobierno, esto es, el BCE, se verá obligado - al momento del pago de los impuestos, dos años después de emitido el dinero paralelo- a aceptar el dólar ecuatoriano a la paridad 1 por 1 por dólar estadounidense, aunque en el mercado no necesariamente rija esa equivalencia. ${ }^{30}$ Desde esta perspectiva, ese tipo de dinero complementario - en alguna medida - es un instrumento por medio del cual el gobierno convierte parte de sus ingresos tributarios futuros en capacidad de gasto presente, y esto contribuirá - inversiones productivas de por medio- a reactivar el aparato productivo y a generar empleo, sobre todo si de por medio está un acuerdo productivo nacional con pequeñas y medianas empresas, que son las que más empleo generan. Tengamos en mente que, según las estadísticas de empleo y el censo económico del INEC, las empresas pequeñas, de 1 a 9 empleados, que representan el 95,4\% de las empresas existentes, generan el 69,1\% del empleo; las empresas de 10 a 99 empleados, que son apenas un 4,2\% de las empresas existentes, dan empleo a un 10,4\%; y el resto de las empresas, de más de 100 empleados, representan solo un $0,4 \%$ de los establecimientos y apenas otorgan un $20,6 \%$ del empleo.

\section{AMPLIACIÓN DEL IMPACTO MONETARIO SECUNDARIO}

La viabilidad inicial y la sostenibilidad en el tiempo del sistema monetario paralelo a escala nacional estarían garantizadas por varios factores. Según datos del INEC, para 2015 se registraron alrededor de 8 millones de personas con al menos un teléfono móvil activado. Esto haría posible realizar transacciones en casi todo el país - para 2013, 86,4\% de hogares tenían, al menos, un teléfono celular-, a través de la amplia red de agencias, cajeros automáticos y agentes del вСЕ y otros organismos públicos —alrededor de 7000 puntos a nivel nacional-.$^{31}$ A esto se sumarían las generalizadas campañas educativas y las reformas legales e institucionales que las precederán; por cierto, a este amplio grupo de entidades con capacidad de consolidar el sistema se añadirían las cooperativas de ahorro y crédito, así como las cajas de ahorro.

¿Pero quiénes van a aceptar esa cuasimoneda después del período inicial ? $^{32}$ Para comenzar, el Estado permitirá su uso para el pago de los bienes y servicios que generan las empresas públicas, no así para el pago de impuestos en un inicio. Luego, debe jugar un papel esencial el BCE, muchos meses antes de iniciar el proceso efectivo, para convencer a las empresas que les será muy ventajosa su incorporación al sistema frente a las que no lo hacen, básicamente porque pagarán menos IVA — cuatro puntos porcentuales menos a los vigentes - a sus proveedores y porque podrán ganar una mayor clientela frente a sus competidores que no poseen la billetera electrónica del вСE. Para eso bastará que el banco central comprometa anticipadamente a participar a empresas privadas que generan bienes y servicios sujetos al IVA en cada una de las principales ramas económicas: medios de transporte, ferreterías, supermercados, farmacias, hospitales, instituciones educativas, restaurantes. También los oligopolios del sector público - agua, electricidad, teléfonos, combustibles - se incorporarán desde el inicio al sistema. A su vez, estas empresas usarán ese medio para pagar a sus proveedores a un precio en el que el IVA ya no sea - lo repetimos- del 14\%, sino solo del 10\%. 
Por cierto que pueden adherirse al sistema todas las empresas y personas dispuestas a beneficiarse con ese peculiar «descuento», aparte de la comodidad, seguridad y velocidad que ofrece la billetera electrónica. Sin duda, más temprano que tarde, la mayoría de empresas se plegarán al sistema, sobre todo por el ahorro en impuestos indirectos — que además son regresivosy como reacción a la paulatina pérdida de su tajada en el mercado por acción de sus competidores inscritos si no participan del sistema. Lo mismo sucederá con el resto de la población, tal como los trabajadores independientes y las amas de casa; en este punto hay que resaltar la necesidad de una permanente campaña gubernamental para seguir incorporando empresas sobre todo pequeñas y medianas, evitando que sean las grandes empresas las principales beneficiarias de este sistema. La formalización de varias pymes, profesionales independientes y personas se daría complementando el sistema electrónico con el de factura electrónica y un proceso simplísimo de declaración tributaria basado en la información de sus transacciones. Todo esto llevará también a un aumento vertiginoso de las transacciones «invisibles» de este tipo entre personas particulares, sin necesidad de recurrir a la banca privada y sin tener que pagar los elevados costos que sus servicios implican. Esta vía podría ser un antecedente potente para introducir el EC\$ en ámbitos cada vez más grandes.

Desde un inicio es de extrema importancia convencer a la población de las bondades del programa, en especial a las empresas privadas, cuyo compromiso para el éxito del sistema es esencial para que acepten parte de los EC $\$$ a cambio de sus productos y servicios. El dinero, tengamos siempre presente, más que un medio para atesorar, es un medio que debería asegurar la circulación, desde la esfera de la producción a la del consumo. A partir de esta sencilla pero profunda reflexión, Silvio Gesell propuso el empleo de un sistema monetario paralelo creado y sostenido desde las comunidades. El buscaba que, cuanto antes, con esta moneda paralela se reactive rápidamente la economía local. ${ }^{33}$ Tal como proponemos nosotros con este sistema bimonetario que permitiría aumentar las ventas de las empresas, tanto por la demanda de los directamente beneficiados por el sistema — los empleados públicos_, como por los beneficiarios indirectos - los desempleados que logran acceder a un puesto como consecuencia de la reactivación de la economía por la expansión de la demanda agregada efectiva-. Por el efecto multiplicador no solo se beneficiarían los productores de bienes y servicios finales, sino asimismo los de insumos y equipos y maquinarias, con lo que se estimularía también la inversión privada y las exportaciones.

Es fundamental entender que, desde ese proceso, el gobierno dispone de cada vez más divisas - de us\$-, lo que le permitiría usar parte de lo que no ha tenido que gastar — por haber pagado en dinero electrónico a los empleados y, eventualmente, a los proveedores del Estadoen diversas posibilidades de asignación como, por ejemplo, aumentar sus reservas internacionales netas, incrementar la inversión pública y el gasto relacionado con sus políticas sociales, establecer un fondo de estabilización económica creciente de indudable utilidad frente a potenciales choques externos, ${ }^{34}$ etc. Nótese, sin embargo, que al aumentar la aceptación del programa caerá la demanda monetaria — aumentará la velocidad de circulación del cuasidinero-, generándose un desequilibrio en el mercado de dinero, pues la oferta monetaria también ha aumentado. El ajuste solo se lograría aumentando levemente los precios —inflación- y/o con el incremento del PIB — recuperación económica—. Dada la capacidad ociosa de producción 
de la economía - el PIB potencial es muy superior al PIB efectivo- es probable que la última opción sea la más realista, teniendo en cuenta también que la tasa de interés real estaría cayendo; por cierto que se necesita una clara estrategia reactivadora del aparato productivo, que no reaccionará solo con un mayor volumen de circulante.

Si bien disminuirá la presión tributaria por la drástica reducción del IVA, se espera que el vacío se cubra en parte por la reactivación económica y, de otra manera, por la reforma fiscal integral que realizaría el gobierno, a fin de contar con impuestos directos y progresivos. No puede ser que el grueso de los ingresos fiscales provenga de los impuestos indirectos - como el IVA- solo porque son más fáciles de recaudar, cuando todos sabemos que son distributivamente regresivos. ${ }^{35}$ Valga una breve digresión sobre el tipo de cambio que podría establecerse entre el EC\$ y el us\$. Inicialmente, sin duda, al pagar las remuneraciones de los empleados públicos se calcula a la paridad, un EC\$ por un US\$. En cambio, en la mayoría de todas las demás condiciones, cuando los agentes económicos — consumidores, empresarios, inversionistas, instituciones sin fines de lucro- utilicen los EC\$ para otros fines, serán las fuerzas de la oferta y la demanda las que determinarán el tipo de cambio entre ambos medios de pago. En este punto habrá que tener mucho cuidado para que no vuelvan a aparecer aquellos grupos de poder que lucran de espacios en donde puede aflorar la especulación.

Es probable que, en un inicio y por falta de confianza, se desplome el EC\$ respecto del us\$, pero a la larga se aproximará a la paridad, pues quienes tienen más poder de compra lo adquirirán inicialmente a un tipo de cambio bajo, pero con la creciente demanda de EC\$ llevarían su precio al alza. En tal sentido, el sistema aquí expuesto posee una especie de «estabilizador automático», el que impedirá una expansión exagerada de los EC\$. Lo que se puede determinar en función a los límites de aprobación del EC\$ por parte de las empresas privadas, las que no los aceptarán más allá de un cierto punto, una vez que hayan logrado satisfacer sus compromisos con el fisco. Lo que quiere decir que la paridad inicial no será fija y solo se aplica cuando se emite - acredita - la «moneda paralela» para pagarle sus remuneraciones a los funcionarios del sector público y, ya mucho más tarde, cuando se redime por concepto de pago de impuestos. Esto último solo sucederá a los dos años de entregada cada tanda de EC\$. Como ya lo dijimos, si se redimieran de inmediato, todo lo que se lograría es reducir —inmediatamente después de iniciado el «experimento»— los ingresos del gobierno por el mismo monto con el que se benefician mensualmente los empleados públicos. Una vez obtenida la confianza de los agentes económicos, en el sentido que efectivamente les resulta beneficiosa y posible la compra con rebaja de las mercancías sujetas al IVA, es posible procesar avances más profundos en el sistema. Lo que interesa es que aumente el número de empresas que reciben ese medio de cambio complementario, que puedan gastárselo con «descuento» en la compra a sus proveedores y así sucesivamente. A la larga, todo el que recibe EC\$ puede transarlo con esa ventaja, ${ }^{36}$ generando un círculo virtuoso.

Una primera modificación, que se repetirá de tiempo en tiempo, consistirá en aumentar la proporción de EC\$ que se le pagará al empleado público. Del 10\% inicial sobre el total de su remuneración, se pasaría a un $20 \%$ y así, sucesivamente, hasta llegar a un máximo sostenible - quizá del 40\% - para evitar una exagerada emisión de EC\$. En ese caso, podrían generarse algunas molestias de parte de los empleados públicos ya que recibirán $40 \%$ menos us\$ 
que en la fase inicial; pero como ya lo dijimos, la entrega de EC\$ será mayor para quienes más ganan. Nótese, sin embargo, que el banco central podría - a fin de no cargar en exceso a los empleados públicos con EC\$- asignarle a otros agentes económicos una parte en esta moneda paralela. En primer lugar, podría incorporar al sistema a los jubilados del sector público, a los trabajadores de las empresas públicas y/o a la fuerza pública, a cada uno de los cuales se les pagaría un 10 o 20\% de sus remuneraciones en EC\$. De otra parte, más interesante y provechoso podría ser que, como complemento, el gobierno le pague a sus proveedores del sector privado una parte en EC\$. Se podría empezar con el 10\% o incluso algo más, negociando con ellos según las condiciones de la economía y los propios requerimientos de liquidez de los proveedores. Ciertamente que para los proveedores esta posibilidad resulta mejor que la situación actual, en la que son largas las demoras en los pagos, que resultan hasta letales para sus empresas. Aquí se tendrá que tomar en cuenta la existencia de pequeños proveedores con fuerte vínculo en la «economía informal» y que posiblemente tengan una mayor presión a recibir dólares líquidos.

ETAPA DE CONSOLIDACIÓN Y CONVERSIÓN DEL DÓLAR ECUATORIANO EN MONEDA OFICIAL

Llegará un momento, digamos que después de dos o tres años de inaugurado el EC\$, que el sistema habrá madurado lo suficiente por la creciente participación de más agentes económicos en los mercados de la moneda complementaria. Es aquí donde recién entramos a las consecuencias más importantes de la propuesta en torno al dinero paralelo, en la medida que desde ese momento se iniciará su proceso de conversión en moneda oficial. Esa «maduración»se caracterizaría por varios factores: que se haya generado una confianza generalizada en el EC\$ por parte de la población; que se haya establecido y consolidado todo el sistema institucional que haga funcionar fluidamente el sistema monetario «ampliado»; que se haya incorporado una masa crítica mínima de empresas dispuestas a aceptar el EC $\$$ para vender -y comprar- bienes y servicios, así como para pagar impuestos; etcétera. Como criterio de esta fase del proceso, diríamos que el EC\$ ha logrado una participación del 30 a 40\% de la masa monetaria total, cayendo la del us $\$$ al 70 o $60 \%$. Cumplidas estas precondiciones se puede profundizar los mecanismos del sistema. Como tal, aquí estriba la esencia de la propuesta: que el gobierno logre «liberar» un monto importante de us\$ que servirían para alentar la inversión pública, incluso poniendo al día el pago a proveedores. Así, una ventaja del esquema es que la «emisión» de EC\$ acabaría, tanto con la latente deflación —inflación negativa- que comienza a sentirse en la economía desde 2015, como con la estrecha liquidez que desacelera el ritmo de la actividad productiva.

En este punto hay que tener en cuenta que, 24 meses después de emitida cada tanda mensual de EC\$, caduca su valor - y uso para compras con descuento del IVA- si no se utiliza para el pago de impuestos. Si bien esto reduce la recaudación tributaria ya que ésta se cotiza en us\$ en una proporción del 1 por 1, la ventaja es que así no aumentaría a niveles insostenibles la masa monetaria. Éste es uno de los puntos más delicados y discutibles de esta propuesta. Más adelante añadiremos algunas medidas adicionales para evitar una expansión exagerada de la masa monetaria, entendida en este caso como la sumatoria de us\$ y EC\$. Debe quedar muy claro que el sistema financiero privado cumplirá su papel tradicional en materia de depósitos 
y colocaciones, pero únicamente en us $\$ .{ }^{37}$ Como no hay la posibilidad de realizar depósitos o préstamos en EC\$, la banca privada no participa propiamente en el circuito del dinero electrónico paralelo, el que es autocontenido entre el $\mathrm{BCE}$, la banca comercial pública, las cooperativas de ahorro y crédito, y los agentes económicos no financieros. Por cierto que todo este sistema funcionaría de manera más eficiente si existieran mercados no oligopolizados, es decir, más desconcentrados; pero ésa es otra tarea pendiente y que rebasa el ámbito de este artículo y debe afrontarse con otros mecanismos - y leyes específicas para ese efecto-.

Con ello, entramos al meollo del punto culminante del proceso de establecimiento de una moneda de curso forzoso, en que se deberá convertir el EC\$, así como del manejo de la política monetaria en el nuevo esquema monetario dual. Sin duda, serán múltiples los cuestionamientos a esta propuesta. La primera y más importante se refiere al hecho que su mecánica sería altamente inflacionaria y que, incluso, podría derivar en hiperinflación..$^{38}$ En efecto, un manejo inadecuado, podría terminar así; sin embargo, contra lo que piensan los economistas ortodoxos, son variados los argumentos en contra. De partida, debe quedar claro que en este caso el stock de la masa monetaria, en un determinado momento, viene dado por dos tipos de flujos, el de las reservas internacionales - derivadas de los déficits o superávits de balanza de pagos - y el de la emisión o contracción de los flujos de dinero electrónico complementario.

Es así que un déficit externo - tan común en Ecuador - reduce la masa monetaria y que, en la actualidad, como hemos visto, se trata de paliar esta situación recurriendo al endeudamiento externo; otras soluciones, como incrementar exportaciones o aumentar el flujo de inversión extranjera toman tiempo y tampoco son una panacea como reza el discurso dominante. Vistas así las cosas, esa contracción quedaría compensada - parcial o totalmente - por el incremento de la emisión paralela del EC\$. De manera que no habrá mayor problema inflacionario si el país sufre una brecha externa negativa, que se comprima la masa monetaria en us\$. Por lo demás, como consecuencia de la ralentización de la economía, se dispone de una elevada capacidad ociosa de producción, lo que otorga espacio para incrementar sustancialmente la demanda agregada, tanto por el lado fiscal como por el monetario, sin generar presión sobre los precios sino hasta que se alcance el pleno empleo y el producto potencial.

En cambio, si se presenta un superávit de la balanza de pagos y/o la expansión del dinero electrónico es «exagerada», tendríamos un incremento de la masa monetaria que influiría para mal sobre el índice inflacionario si se llega a un punto en el que el PIB efectivo rebasa el PIB potencial. Ello obligaría a la intervención estatal. Concretamente, el всE deberá ajustar al alza la tasa de encaje de los depósitos de la banca en us\$. De un encaje que representa el $5 \%$ de los depósitos de la gran banca privada, ${ }^{39}$ el directorio de la institución tendría que aumentarlo en uno o dos puntos porcentuales dependiendo de las circunstancias; y cada trimestre o semestre debe evaluar la conveniencia de hacerlo según la evolución de las reservas internacionales —en particular, la «posición de cambio»— y la emisión monetaria paralela. Con esa medida se reduce el multiplicador monetario de la banca privada, para el caso de los depósitos en us $\$^{40}$, sin afectar la evolución de los flujos en EC\$. Es ésa la mejor forma de evitar presiones inflacionarias en este sistema bimonetario, a la vez que se estimula una mayor circulación absoluta y relativa al us $\$$ del EC $\$ .^{41}$

De ahí que, con la introducción de la moneda paralela, las responsabilidades del вСE aumentarían, ya que tiene que poner la vista en dos flancos: la evolución de la masa monetaria en 
Us\$ y la correspondiente a los EC\$. Mientras que la primera es exógena —-dependiendo básicamente del intercambio externo- - y se refiere a los flujos internacionales de divisas - tal como los recoge la balanza de pagos-, la segunda es endógena, ya que depende no solo de la emisión del вСE, sino también del comportamiento de los agentes económicos en su uso del EC\$. ${ }^{42}$

De una parte, el BCE debe afrontar la volatilidad de los variados flujos relacionados con las transacciones con el exterior, ${ }^{43}$ la que debe ser suavizada o eliminada por la política monetaria en EC\$ y su emisión. Es en este aspecto que el papel que desempeñará el BCE será fundamental y que debe seguir con una política de permanente ajuste monetario para evitar sea el exceso o la estrechez de la liquidez. Paradójicamente, la coyuntura más compleja para el BCE sería aquella en que hubiese un contundente superávit de balanza de pagos — sea por el aumento de los precios y las cantidades exportadas de petróleo, por ejemplo- en la que aumentaría sustancialmente la masa monetaria -en us\$-. Una situación de esta naturaleza obligaría a reducir el crecimiento de la emisión del dinero paralelo — de EC\$—. Este sistema bien podría tener en mente la experiencia suiza con el WIR, antes mencionada. ${ }^{44}$ Además, con este esquema bimonetario el gobierno - a través del BCE - lograría diversos objetivos, dos de los cuales cabe explicitar.

En primer lugar, el más importante, es que su directorio dispondría de un margen de maniobra para ejercer política monetaria, lo que conseguiría aumentando o disminuyendo el porcentaje de dinero electrónico que emitiría para cancelar las remuneraciones de los empleados del sector público. En un inicio hemos planteado que el porcentaje de «emisión» será reducido $-10 \%$ de las remuneraciones públicas-, el que puede y debe aumentar a medida que se asienta el modelo por la confianza ganada entre los agentes económicos que utilizan cada vez más el dinero paralelo; pero, en una fase avanzada, deberá detenerse el proceso de aumento de la tajada, quizás cuando el porcentaje haya alcanzado el $40 \%$, por ejemplo, tasa que se fijaría como tope para evitar una exagerada emisión monetaria.

En segundo lugar, téngase presente que para entonces el gobierno poseerá varias herramientas adicionales para evitar que la masa monetaria se incremente excesivamente. Una de ellas consiste en disminuir el porcentaje de EC\$ que pagarán a los empleados públicos; otra consistiría en reducir el «descuento» por IVA — por ejemplo, en vez de beneficiar al cuentahabiente con una reducción de 4 puntos porcentuales, solo le asegurarían 2 puntos porcentuales-; una tercera forma, más extrema, consistiría en recortar el período de «maduración» de cada emisión de la segunda moneda, con lo que los poseedores pueden pagar impuestos en un tiempo menor a los dos años y el gobierno recogería más rápidamente los EC\$; y una última, podría consistir en subir la tasa de encaje en us\$ que la banca privada debe depositar en el banco central.

El momento más delicado que deberá afrontar el gobierno en relación a sus finanzas se presentará cuando se comiencen a redimir los EC\$ por parte del gobierno, compromiso que asumió cuando se inició el programa al señalar que se cambiará «1 a 1» un EC\$ por un US\$, una vez cumplidos dos años desde que fuera emitido y entregado a los empleados y jubilados del sector público. Mientras más EC\$ se añadan al flujo monetario — real o aparentemente-, se ejercerá una mayor presión sobre el equilibrio del mercado monetario y de las cuentas fiscales. Ciertamente se considera que — dado que el programa reactivará la economía- los de 
ahí derivados mayores ingresos públicos permitirán afrontar parte de la presión, evitando los déficits antes de que se vuelvan incontenibles. Quizá tres o cuatro años después de puesto en marcha el sistema, en el mejor de los casos, una vez saneada la economía, eliminada la deflación y equilibradas las cuentas fiscal y externa, cuando estén sentadas las bases para un crecimiento económico sostenido, ${ }^{45}$ caben dos vías para continuar, como anotamos antes. Una sería regresar al circuito del dólar de jure, eliminando la moneda paralela; y la otra sería recuperar - aunque solo sea parcialmente - su control relativo de las políticas monetaria y cambiaria, que es lo que proponemos aquí.

Con la maduración del proceso, cuando la masa monetaria en EC\$ alcance el 40\% o más, se deberá iniciar el manejo monetario en base a las políticas de metas de inflación, ${ }^{46}$ como sucede en muchos países. ${ }^{47}$ Inicialmente, será un manejo muy complejo y limitado, como lo experimentaron varios países con una elevada dolarización de facto. Nuevamente en este caso se requeriría un directorio del banco central muy selecto y comprometido con el país, no con intereses particulares. ${ }^{48}$ En última instancia, de no funcionar esas políticas, el gobierno tendrá que adoptar medidas drásticas, sea a través del control de capitales —en especial, de los desestabilizantes flujos de corto plazo—, sea por medio del establecimiento de una «tasa Tobin», como acontece ya en Ecuador con el impuesto a la salida de capitales — del 5\%-.

\section{NOTA AL MARGEN: DESPLAZANDO AL GRAN CAPITAL FINANCIERO}

Aquí ciertamente surgirán conflictos — aún antes de la puesta en marcha de este sistemaentre los representantes del gobierno - $\mathrm{el} \mathrm{BCE}$ - con las instituciones financieras privadas, porque éstas perderán buena parte de su clientela, precisamente de aquellos agentes económicos que irán reconociendo las ventajas del sistema; sobre todo porque éste provocará una reducción de las exageradas cargas que cobran los bancos por sus transacciones, especialmente por el uso de tarjetas de crédito o de débito. Pero debe quedar claro que, en la práctica, no todo el monto que contiene cada billetera electrónica se gastará por medio de ella, ya que hay compromisos y contratos de endeudamientos que los agentes económicos han firmado previamente - o requerirán a futuro- en us $\$$ y cuyo servicio se seguirá procesando en su mayoría a través de la banca privada.

El impacto que este sistema ejercerá sobre el sistema financiero es difícil calibrar ex ante. Es evidente que las funciones del conglomerado financiero privado se reducirán en alguna medida y que verán recortado su stock de depósitos, aunque mantendrán, en lo esencial, el grueso de sus actividades más rentables: el otorgamiento de créditos y el negocio cambiario. ${ }^{49}$ Es probable que su actual tasa de ganancia sectorial descienda al promedio que rige en el resto de ramas de la economía «moderna y formal». Lo que en la práctica debería llevar a que, además, tendrán que aumentar su competitividad, obligándolos a reducir, tanto los niveles como las abismales brechas que acostumbran fijar entre las tasas de interés activas y pasivas, como a las que determinan entre los tipos de cambio de venta y compra de moneda extranjera. Pero también podrá suceder lo contrario - dado su poder y considerando que disponen de lazos y alianzas con los oligopolios de otras ramas económicas - que las brechas aumenten porque deciden incrementar el margen, subiendo - ceteris paribus - la tasa activa de interés y/o el precio de venta del us\$ con respecto al EC\$. De insistir en esas políticas — sin duda concertadas entre los 
principales bancos oligopólicos privados - habrá que desplegar las medidas que sean necesarias, incluyendo el control del flujo de us\$ por parte del propio banco central — por ejemplo, limitar acceso de tales dólares a grandes importadores-, aunque cabe señalar que, de mantener el curso de la política propuesta en estas páginas, seguirán perdiendo clientela, la que será atendida crecientemente por la banca pública y, en no menor medida, por las cooperativas de ahorro y mutualistas.

En el caso extremo, en reacción a las políticas de la banca, podría llegar el momento en el que el BCE asumiera parte de esos negocios en asociación con los bancos comerciales del Estado. Como tal, por la creciente presencia del всE - Banco Nacional de Fomento (ahora BanEcuador), Corporación Financiera Nacional y la banca comercial pública-, éste asumiría una especie de contrapoder al que ejercen las instituciones financieras privadas, con lo que, tal como indicamos arriba, las induciría a reducir las comisiones, las brechas y demás costos exagerados del actual negocio financiero nacional. Así, en ese escenario, mientras el sistema bancario privado competiría principalmente usando us\$, el sistema bancario público lo haría usando EC\$. Sin duda, dadas la condiciones económicas actuales y el «saber establecido», esta propuesta solo podrá cristalizarse si se crean las mencionadas reformas institucionales y sociopolíticas para viabilizarlas.

\section{CONCLUSIONES TENTATIVAS}

Entenderán nuestros lectores que hemos presentado apenas un bosquejo de lo que significaría instrumentar un sistema paralelo de dinero - reconociendo que el dinero no es neutro- con la expectativa que Ecuador recupere paulatinamente su soberanía en los campos monetario y cambiario, como un medio para poder dar respuestas más efectivas a las cambiantes situaciones de la economía..$^{\circ}$ Lo que hemos argumentado en el texto es que el mecanismo de la moneda complementaria al us\$ permitiría suavizar las drásticas condiciones de ajuste fiscal que deberán aplicar en un futuro cercano las autoridades, con lo que Ecuador podría remontar su crisis fiscal y, por añadidura, evitar la recesión y regresar lenta y parcialmente a una moneda propia - de curso legal—, sin tener que pagar los costos que implicaría un ajuste ortodoxo.

El desafío que representa este programa apenas se transluce en la exposición. Habrá que especificar con más detalle todos los aspectos complejos y polémicos del caso, como son la dinámica política que desataría el programa, los problemas legales e institucionales que implica, así como las consecuencias sociales a que daría lugar, entre otros muchos elementos críticos. Si bien hemos centrado nuestra exposición en los principales aspectos económicos, aún falta completarla con un análisis cuantitativo que permita - en base a un modelo macroeconómico- proyectar las tendencias de las variables básicas que derivarían de la propuesta y que permitirían validar o cuestionar sus principios básicos: las cuentas fiscal, monetaria y de balanza de pagos, de donde se obtendría la evolución de variables claves de la macroeconomía, tales como las reservas internacionales, las tasas de interés, la inflación y el crecimiento.

Además de esos análisis, quedan varios puntos pendientes para nuevas investigaciones. Por ejemplo: ¿Hasta qué punto podemos confiar en el efecto multiplicador si la producción doméstica es altamente dependiente de las importaciones? ¿Cuál sería el papel de la banca privada 
cuando el sistema bimonetario esté en pleno funcionamiento y cuál sería su vínculo con la banca pública? ¿Los agentes económicos podrían sentir «pánico financiero» y presionar a una corrida bancaria apenas se paguen los primeros EC\$ a los funcionarios públicos? ¿Qué pasaría con el esquema si no son suficientes dos años para la reactivación, especialmente al tener la presión fiscal por el reconocimiento de la paridad 1:1 en el pago de impuestos? ¿Qué tipo de administración del banco central sería la más idónea al tener un esquema bimonetario? ¿Hasta qué punto el dinero en la economía ecuatoriana con moneda paralela es endógeno o exógeno? Éstas y otras cuestiones deben ser detenidamente analizadas.

Sería iluso creer que con un medio de cambio paralelo al us\$, por más que lo vaya desplazando paulatinamente, se puedan resolver los principales problemas de la economía y sociedad ecuatorianas. Este sistema no es la panacea, pero tampoco es un placebo. Como es evidente, nuestro programa-sugerencia de una segunda moneda al us\$ implica una transformación de fondo del sistema monetario ecuatoriano, partiendo de algunos elementos básicos de su economía e institucionalidad, pero ciertamente no logrará resolver todos sus problemas, si bien representará uno de los prerrequisitos básicos para ello. En lo fundamental se trata de un instrumento para acelerar la salida de la crisis socioeconómica ecuatoriana, contribuyendo a remontarla y a reactivar la anémica economía, gracias a la expansión de la liquidez, la reducción de la capacidad productiva ociosa y el alivio fiscal que permitiría. En última instancia, nuestros lectores comprenderán que en este campo no debe olvidarse que se trata finalmente de conflictos políticos que se desatarán a varios niveles. Como podrían ser, uno, intelectual, entre los tecnoideólogos ortodoxos — neoclásicos y keynesianos - y los heterodoxos - poskeynesianos y neomarxisas-; dos, entre el capital financiero y el propiamente productivo; $y$, tres, entre los grandes grupos de poder y el poder popular.

Es evidente que el país necesita llevar a cabo — también en forma paralela a lo aquí propuesto- cambios estructurales profundos bien conocidos, pero poco practicados. Requerimos la reconfiguración fiscal - dándole un mayor peso a los impuestos directos que a los indirectos-; la asignación adecuada del gasto público —incrementando la verdadera inversión vis a vis el gasto corriente o la inversión espuria-; la transformación efectiva de la matriz productiva que dé paso a una economía concentrada en múltiples sectores y menos dependiente del exterior - sobre la base de encadenamientos hirschmanianos y ventajas comparativas dinámicas, más que, como hasta ahora, estáticas_; la redistribución del ingreso y la riqueza —incluida la reforma agraria - para asegurar un mercado interno más extendido; la desconcentración de los mercados; la descentralización política, etc. A lo anterior se suman las urgentes y profundas reformas judicial, educativa, electoral y de los partidos políticos, entre otras. A lo que habría que añadir una lucha sin cuartel contra la corrupción y el clientelismo-rentismo. Todo ello va bastante más allá de la recuperación de la soberanía monetaria, que bien puede lograr avances en la productividad y competitividad de la economía, pero tampoco va mucho más allá.

Por supuesto que hay que superar las nefastas consecuencias que son bien conocidas del modelo primario exportador vigente, que siempre ha terminado materializándose en la «maldición de los recursos naturales». ${ }^{51}$ Esto nos conduce necesariamente a diseñar y poner en marcha estrategias posextractivistas. Bien sabemos que la explotación y exportación de materias primas, comenzando con petróleo y minerales, son el destino endiablado de países que 
no han superado dicha «maldición» para construir sociedades democráticas, la única vía para que todos los seres vivos tengan una vida digna.

\section{A MANERA DE ANEXO}

UNA DIGRESIÓN ADICIONAL: MIRANDO AL FUTURO Y LA «PROPUESTA ITALIANA»

Cada vez es más claro que habrá que afrontar la gravedad de la crisis y adoptar políticas de ajuste y estabilización económica en el Ecuador. El reto es evitar que se apliquen políticas de corte ortodoxo, cuyas consecuencias impactarán en la mayoría de la población. Por lo tanto, habría que construir bases alternativas para desplegar otro tipo de política económica que no afecte a las grandes mayorías, en la que bien funcionaría la propuesta que aquí hemos esbozado, orientada a conseguir un respiro monetario con el EC\$. El sistema bimonetario, sintetizado en las líneas anteriores, podría complementarse con las ideas que propone un grupo de economistas italianos en base a lo que se conoce como la «moneda fiscal». Esta es una propuesta de alguna forma emparentada con nuestro programa, pero que va más a fondo en sus principios y consecuencias. Más que por razones inmediatistas, conviene esbozar aquí su planteamiento en forma breve, dada su importancia sociopolítica y el desafío intelectual y político que implica.

La propuesta de los economistas de la Asociación Paolo Sylos Labini ${ }^{52}$ parte de la afirmación de acuerdo a la cual, «para afrontar la crisis se requiere, incluso en el contexto del euro, que cada estado nacional adopte medidas soberanas urgentes para revitalizar la demanda doméstica, la producción y el empleo» (Bossone et al., 2015, p. 3). Con ese fin, proponen la emisión, por parte del gobierno nacional, de una moneda paralela al euro para los países «mediterráneos», a fin de salir de la crisis estimulando la demanda agregada interna. Más concretamente la denominan Certificados de Crédito Tributario (тСС, por su acrónimo del inglés Tax Credit Certificates) que servirían de cuasimonedas, complementarias al euro y que no generarían deuda alguna para quienes la recibirán; es decir, serán gratuitas.

Sugieren que esos certificados se distribuyan, sea al azar — como el Helicopter money de M. Friedman, 1969-, sea directa y preferentemente a la población de menores ingresos, tanto porque son los más necesitados, como porque su propensión media y marginal a consumir es la más alta de la sociedad — con lo que el multiplicador del ingreso será mayor-. De ahí su referencia al «dinero fiscal libre», que ellos consideran debe entregarse sin costo a los trabajadores asalariados y desempleados, a los jubilados, a los autoempleados — trabajadores independientes- y a ciertas empresas. En este último caso, se les obsequiará esos certificados en función a la proporción asignada a sus costos laborales, con lo que se reducirían drásticamente sus gastos en fuerza de trabajo y se aumentaría su competitividad -incrementando las exportaciones-, a la vez que se limitaría el impacto en la balanza comercial como consecuencia del crecimiento de las importaciones por el aumento del PIB. De esta manera, la característica principal de tales certificados es que le asegurarán - a los hogares de menores ingresos y a las empresas intensivas en trabajo- un acceso adicional e inmediato de un instrumento que aumentará su efectiva capacidad y poder de compra. 
De otra parte, esos TCC se usarían para resolver cualquier obligación financiera con las administraciones nacionales públicas - tales como impuestos estatales y locales, contribuciones al seguro social, sanciones pecuniarias y demás - dos o tres años después de su emisión, pero que serían inmediatamente convertibles en euros para el gasto. Más concretamente, refiriéndose al caso italiano, el gobierno emitiría certificados por alrededor del $5 \%$ del PIB durante el primer año e incrementaría la emisión en los años subsiguientes hasta un tope del 10\% del PIB y siempre que se observe una recuperación sostenida de la producción y el empleo. Este nuevo instrumento emitido por el Estado con el propósito de reducir la carga fiscal fluirá directamente a los bolsillos de las personas, sin tener que convertirse en nueva deuda. En ese sentido, la emisión de los certificados iría a contracorriente de la austeridad impuesta por la Unión Europea y resolvería el problema de la escasez de liquidez que actualmente está afectando la economía de los países más débiles de la eurozona y que el sistema bancario ha probado que es incapaz de resolver: refinanciado por el Banco Central Europeo, ha invertido esos flujos mayoritariamente en nuevos fondos disponibles en activos financieros, mientras continuaron comprimiendo el otorgamiento de créditos que hubieran favorecido a la economía real.

Los certificados servirán para resolver obligaciones con el Estado, pudiéndose convertir en euros en el mercado financiero. Con lo que serían un nuevo producto financiero que el Estado se comprometerá a seguir emitiendo sobre una base permanente, pero variándola gradualmente, según la respuesta de la economía a ese estímulo..$^{53}$ Para el caso específico de Italia, para ilustrar la magnitud del dinero involucrado en el proyecto, los autores proponen una emisión de 200.000 millones de euros para el bienio 2015-2016 - recuerde que la propuesta fue planteada en 2014-. Ese flujo sería asignado de la siguiente manera: €70.000 millones para los empleados, en proporción inversa a su ingreso tributariamente imponible; €80.000 millones a los empleadores del sector privado - esta cifra reduciría en $18 \%$ el costo laboral, equivalente a la brecha competitiva de Italia frente a Alemania-; y €50.00o millones para otros usos que estimulen la demanda —inversión pública nueva, esquemas de ingreso asegurado, apoyo a iniciativas del sector privado en regiones deprimidas, dando preferencia a proyectos de utilidad social fáciles de implementar-.

A ese ritmo de emisión anual de €200.000 millones, se generaría un stock de certificados en circulación por un monto de $€ 400.000$ millones, que equivale a la mitad de los ingresos fiscales totales de Italia. Asumiendo un multiplicador del ingreso de 1,3, el PIB se recuperaría en un $15 \%$ en sus primeros tres años, con una caída de cinco puntos porcentuales en el desempleo y una balanza comercial en equilibrio. El déficit fiscal —-definido como la diferencia entre los ingresos y gastos fiscales en euros - se reduciría a cero ya hacia fines de 2015 y la deuda pública comenzaría a caer en términos porcentuales respecto al PIB. De manera que este sistema de certificados es una manera de replicar los efectos de una devaluación monetaria, en la medida que estimularía el aumento de las exportaciones, a la vez que evitaría el crecimiento de las importaciones como consecuencia de la recuperación económica.

A pesar de la valía de esta propuesta, consideramos que - en términos generales - adolece de dos puntos débiles si desea aplicarse, sea a Italia o al Ecuador, pero que bien pueden ajustarse si se dispone del tiempo y el personal técnico necesario para enmendarlos. De una parte, la expansión de la moneda paralela parece exagerada y no pensamos que en solo dos 
años puedan restablecerse las cuentas fiscales, en vista de la sustancial rebaja de impuestos de la que se beneficiarían los tenedores de certificados al cumplirse su maduración a dos o tres años vista de su emisión. De otra parte, el «helicóptero monetario» dirigido a grupos específicos de la población requeriría de una institucionalidad y de un banco de datos que no existen en ambos países, aparte de que potencialmente podría dar lugar a su entrega monetaria paternalista y/o a su uso políticamente sesgado y sujeto a corruptelas.

Ahora, cabe destacar que el Ecuador posee una ventaja interesante: a EE. UU. no le importa, en absoluto, la política monetaria ecuatoriana, cosa muy distinta a la importancia que sí podría tener una política monetaria más soberana entre los miembros de la Unión Europea solo recordemos lo que sucedió con Grecia-. Ese hecho de que Ecuador no tenga relevancia para la política monetaria de EE. UU. hace que el país tenga la posibilidad de crear una nueva masa monetaria dentro de sus fronteras sin esperar represalias políticas de EE. UU. a través de ajustes en la emisión mundial de dólares para reajustar los tipos de cambio, por ejemplo.

\section{NOTAS}

1 La dolarización resultó de una decisión arbitraria e inconstitucional. En la Constitución de 1998, Art. 264, se establecía que «La emisión de moneda con poder liberatorio ilimitado será atribución exclusiva del Banco Central. La unidad monetaria es el Sucre, cuya relación de cambio con otras monedas será fijada por el Banco Central». Esa disposición constitucional fue violentada con una ley: el artículo 1 de la ley n. ${ }^{\circ} 4$ para la Transformación Económica del Ecuador, publicada en Registro Oficial Suplemento 34, de 13 de marzo del 200o, ordenó al Banco Central del Ecuador canjear los sucres por dólares a la paridad de $\mathrm{S} / .25 .000$, estableciendo que los dólares norteamericanos circularán en adelante en la república.

2 En esa época, en un curioso escenario de «entontecimiento» generalizado de la sociedad, se cerró la puerta a la búsqueda de alternativas a las propuestas dominantes que provenían del Consenso de Washington. Los autores de este artículo propusieron un esquema para afrontar la crisis y reactivar la economía, el cual pasó prácticamente desapercibido — véase su aporte La hora de la reactivación, 1999-.

3 Recuérdese que en el año 2000 se llegó a afirmar que la dolarización era una vacuna para la hiperinflación, cuando entonces no había condiciones para que se materialice un proceso de tamaña dimensión -véase Acosta y Schuldt, 2000-.

4 Se usan epítetos como «arbitrariedad monetaria», de «maliciosa disposición», de "perfidia», de «engendro monetario", entre otros.

5 A más de Ecuador, solo El Salvador cedió a las tentaciones dolarizadoras en ese momento.

6 Véase el texto de Schuldt (1999), en el que se presentaron - en forma de diálogo- los argumentos a favor y en contra de la dolarización, tal como se venían discutiendo ardorosamente entonces.

7 Una mayor disminución de las tasas de interés en Ecuador se puede lograr regulando y mejorando el costo de la captación de las instituciones financieras, lo que no necesariamente se correlaciona directamente con la dolarización.

8 Cabe conocer que hay muchos países con su propio dólar: Australia, Bahamas, Barbados, Brunei, Canadá, Hong Kong, Liberia, Namibia, Nueva Zelanda, Singapur, Trinidad y Tobago, entre otros.

9 Incluso Friedrich von Hayek (1986) era partidario de una competencia entre monedas emitidas por los bancos privados; propuesta que no la defendemos nosotros en el sentido hayekiano de privatizar la emisión monetaria, por cierto.

10 Recordemos las promesas con las que se impuso la dolarización en el año 200o: estabilización macroeconómica, reactivación inmediata de los sectores productivos, saneamiento bancario, eliminación del déficit fiscal... alcanzando, además, la profundización de reformas estructurales neoliberales y el restablecimiento de la gobernabilidad. Sobre estos planteamientos hay una amplia literatura, pero 
bastaría leer el remitido de prensa del Foro Económico del viernes 7 de enero de 2000, en el diario El Universo de Guayaquil. Muchos de los miembros de dicho foro se han reagrupado ahora en el Foro Prodolarización (https://forodolarizacion.wordpress.com/).

11 Las múltiples opciones abarcan, desde las «millas» y puntos que ofrecen las compañías aéreas y centros comerciales, pasando por los dólares que circulan de facto con monedas domésticas de curso legal, hasta llegar a los dineros electrónicos, tales como los bitcóin.

12 Un valioso repaso histórico de las «monedas paralelas», desde la Antigüedad, pasando por la Edad Media, hasta las hiperinflaciones de posguerra en Europa, puede consultarse en el texto de Von Dem Berge (2014).

13 Economista que fuera el primer Ministro de Economía del gobierno de Alexis Tsipras, durante su primer semestre. Renunció en junio de 2015, tanto por presión de los poderes fácticos de la eurozona especialmente del Ministro de Economía alemán-, como porque estaba en desacuerdo con el premier que aceptó - a pies juntillas - las políticas ortodoxas dictadas por la troika - Banco Central Europeo, Comisión Europea y Fondo Monetario Internacional-.

14 El gobierno griego, inaugurado en enero de 2015 y comandado por el premier A. Tsipras - del partido Siryza-, tuvo que doblegarse ante las amenazas de expulsión de la eurozona y las exigencias de política impuestas por la troika. Véanse las drásticas medidas en el Memorando de Entendimiento (MoU, 2015). 15 Véase, por ejemplo, las reflexiones de Alberto Acosta (2004), así como las de Rafael Correa (2005). 16 Se trata de iniciativas que surgieron y fueron lideradas por dirigentes comunales, directores y activistas de algunas ONG, alcaldes provinciales o distritales, asociaciones de padres de familia de escuelas, académicos tecno-políticos, etc. Incluso, el caso más exitoso, conocido como wIR - Wirtschaftsring Genossenschaft- en Suiza, se dio solo por iniciativa de y para empresas privadas; iniciado a raíz de la Gran Depresión, sigue vigente hasta hoy. Éste sigue funcionando a la perfección hasta hoy y adquiere más vigor en cada proceso de desaceleración económica, cumpliendo un papel contracíclico. Esta red de cooperación económica, basada en los principios de Silvio Gesell (1916), se creó en 1934. Desde 1936, el WIR adquiere condición de banco regulado por la Comisión Suiza de Bancos Confederados. La diferencia con la banca tradicional radica en que la creación de dinero no se da por autorización estatal, sino por la estructura del contrato que firma el prestatario y la voluntad comunitaria de aceptarlo como medio de pago. Así, quien solicita un préstamo intercambia el dinero con bienes o servicios de un miembro de la cooperativa y este a su vez replica el comportamiento con otros miembros. El dinero wIR tiene una relación de uno a uno con el franco suizo y los créditos otorgados pagan una tasa de interés considerablemente baja - o nula si el crédito es de corto plazo-. El banco tiene agencias en toda Suiza y ofrece inversiones, créditos hipotecarios, cuentas de ahorro y corriente para sus afiliados - fundamentalmente pequeñas empresas-, ya sea en francos suizos o en WIR. A ese respecto, véanse los textos de Stodder (2009), Kalinovski (2011) y Christensen (2012a).

17 En el artículo 253 de la Constitución de 1998 se estableció que «el Estado reconocerá las transacciones comerciales por trueque y similares». Reconocimiento que no aparece en la Constitución del 2008. 18 Advertimos al lector que ésta solo es una variante de las muchas que han venido circulando sobre el establecimiento de «monedas paralelas», que son prácticamente desconocidas - o ignoradas- por la mayoría de economistas. A ese respecto, véase el estudio de treinta de estos planteamientos técnicopolíticos, analizados comparativamente por Ludwig Schuster (2013). Desde entonces, especialmente al desatarse la crisis griega, han surgido - sobre todo en 2015 - varias docenas de propuestas más, en algunas de las cuales sustentaremos parcialmente nuestro planteamiento. Las contribuciones más interesantes provienen de los economistas nombrados en el texto y algunos otros que figuran en las referencias. 19 La Constitución de 2008 dice en el Art. 303: «La formulación de las políticas monetaria, crediticia, cambiaria y financiera es facultad exclusiva de la Función Ejecutiva y se instrumentará a través del Banco Central. La ley regulará la circulación de la moneda con poder liberatorio en el territorio ecuatoriano. La ejecución de la política crediticia y financiera también se ejercerá a través de la banca pública. El Banco Central es una persona jurídica de derecho público, cuya organización y funcionamiento será establecido por la ley». De todas formas, esta discusión debe darse con mucha seriedad y responsabilidad, 
teniendo en mente la necesidad de un banco central independiente del poder político y de los poderes económicos.

20 Sin duda, parte de nuestra propuesta, si bien no es un elemento inevitable de ella, consistirá en eliminar paulatinamente - gracias a la tecnología - los billetes de USD 100 y USD 50, siguiendo la iniciativa de Kenneth Rogoff (2016), quien correctamente ha fundamentado que ello permitiría eliminar en buena medida el «lado oscuro» de los billetes y lo que él llama «la maldición del efectivo», refiriéndose a las monedas de alta gradación, porque contribuyen a realizar actividades ilegales, tales como narcotráfico, extorsión, prostitución, corrupción de funcionarios públicos, tráfico humano y, por supuesto, lavado de dinero.

21 Por cierto, habrá que prever formas para evitar que, dentro de este esquema bimonetario, las empresas telefónicas lleguen a controlar indebidamente el sistema y para que no entren en colusión con el sistema financiero privado buscando aprovechar del uso de tipos de cambio diferenciales.

22 A primera vista, puede preocupar esta «emisión inorgánica», pero no es así. Las cifras oficiales del Ministerio de Finanzas, a diciembre 2015, señalan que había 491.520 empleados públicos contabilizados en el Presupuesto General del Estado, que significaron un gasto total de USD 9142 millones. Los ingresos anuales de cada uno ascendieron a USD 18.600 , con lo que mensualmente recibieron USD $1550-4,2$ veces el salario mínimo del país-. Por tanto, si tenemos en cuenta que las remuneraciones anuales del sector público son equivalentes a USD 9100 millones redondeados, el 10\% equivale a USD 910 millones. Cifra que respecto a las especies monetarias en circulación (Mo), que a diciembre de 2015 fueron de USD 11.840 millones, apenas representaría el 7,7\%. En relación a la oferta monetaria (M1), que ascendió a USD 19.041 millones, la relación baja a solo 4,8\%, con lo que no puede considerarse exagerada la emisión de dólares ecuatorianos a través de este mecanismo.

23 No descartamos la participación del sistema cooperativo en este esquema, dentro del cual bien podría contribuir a fortalecer y diversificar el sistema, además de contribuir a que el mismo se difunda a sectores propios de la economía popular y solidaria.

24 Si bien al BCE le costó instalar su sistema - algo más de tres millones de dólares- bien pudo haberlo conseguido prácticamente gratis - sin contar el personal para instrumentarlo y familiarizar a quienes se ocuparán del sistema - acudiendo a las plataformas que ofrecen, por ejemplo, empresas como Cyclos (http://www.cyclos.org/).

25 Otra modalidad de ampliar el sistema - propuesta por Andresen, 2015 - sería que, a manera de «gancho» para entusiasmar a los empleados del sector público, sus ingresos deberían aumentarse, por ejemplo, en $10 \%$ si aceptan el EC\$, con lo que recibirían un sueldo del $110 \%$, en que 80 o 90 puntos porcentuales se desembolsarían en US\$ y 30 o 20 puntos restantes en EC\$. Tal medida permitiría triplicar o duplicar la emisión de EC\$ antes expuesta. Esta variante presenta algunas complicaciones, pues incrementaría aún más la brecha existente entre las remuneraciones del sector púbico vis a vis el privado. Y quizás en este caso se debería reducir el beneficio en el descuento del IVA.

26 La lista de mercancías por las que hay que pagar actualmente el IvA de 14\% en el Ecuador puede consultarse en http://www.eluniverso.com/noticias/2016/o6/o1/nota/5610459/iva-impacta-gasto-hogaresinflacion

27 Lo que podría ser un paso previo a la impresión de billetes de diversas denominaciones, si éste fuera el camino a seguir, considerando siempre el principio de la «maldición del dinero en efectivo» (Rogoff, 2016). Además se podría pensar a dónde direccionar la nueva emisión monetaria: por ejemplo para incrementar el Bono de Desarrollo Humano (BDH) pagándolo en la nueva moneda. Solo tomemos en cuenta que si a los 444.562 beneficiarios del BDH - hubo un fuerte recorte en 2014 dado que en 2013 eran más de 1,2 millones - se les da USD 50 adicionales al mes bajo la forma de EC\$, la emisión monetaria anual llegaría a más de 266,7 millones de esos dólares. Como las personas beneficiarias son de estratos bajos, con toda seguridad el plus del bono se destinaría a gasto de consumo, lo cual podría ayudar a dinamizar la economía, siempre y cuando se transforme este BDH también en un bono productivo (Acosta 2013a). 28 Según datos del BCE, entre 1994 y 1999 el porcentaje de depósitos en dólares respecto al total de depósitos se incrementó de 15,7 a 47,3\%, mientras que en el caso de las colocaciones el incremento fue de 19,9 a $66,5 \%$. 
29 En el caso de la identidad $\mathrm{Mv}=\mathrm{PQ}$, si aumentan $\mathrm{M} \mathrm{y} \mathrm{v}$, aún podemos contener el incremento de $\mathrm{P}$ por el incremento de Q.

30 En la medida que algunos agentes económicos dispongan de un exceso de EC\$, que aún no puedan usar para el pago de impuestos - al equivalente en us\$- por no haber pasado los dos años de "gracia» o por no haber tenido la oportunidad de gastarlos con la rebaja del IVA, puede suceder que los deseen cambiar - con algún otro agente económico - a un precio más bajo que la paridad. Asimismo, otros agentes, por tener alguna deuda o compromiso en us\$, podrían verse forzados a canjear con otra persona o empresa sus EC\$, también a un tipo de cambio menor a la paridad.

31 Nótese, sin embargo, que implícitamente pareceríamos estar «ordenando» que todo el mundo tenga un iPhone - celular o similar-y que lo supiera administrar. ¿No es eso mucho pedir? Efectivamente, analfabetos, discapacitados, niños y ancianos tendrán grandes dificultades o sencillamente serían incapaces de participar en el sistema, por lo que en esos casos se verán obligados a utilizar sus transacciones con billetes en US\$ hasta que se instaure el EC $\$$ de curso forzoso. De todas formas, dependiendo del mecanismo de dinero electrónico por utilizar - por ejemplo, análogo a los sMs-, quizá no sea fundamental que la población use necesariamente teléfonos inteligentes.

32 Lo es porque, a diferencia del dinero propiamente dicho, no se concebirá por los ciudadanos como depósito de valor — sea bajo el colchón, sea porque no rinde intereses-, sino exclusivamente como unidad de medida y medio de pago.

33 Éste consideraba la posibilidad de la «oxidación» de la moneda para alentar su utilización. Esta «oxidación» consiste en una leve depreciación mensual - fija — de la moneda paralela. El objetivo es motivar a quienes poseen dineros paralelos a que los gasten cuanto antes; al acelerar la circulación monetaria - cae la demanda monetaria-, aumenta la demanda agregada. Se desarrolló en pequeñas comunidades de Alemania, Austria y Suiza en plena crisis mundial en los años treinta, destacando el más exitoso, hasta hoy vigente, el mencionado WIR en Suiza.

34 No pensamos en los fondos de estabilización de la época neoliberal, como el FEIREP, que estaban destinados a apuntalar el servicio de la deuda o al menos su cotización en el mercado.

35 En 2015 - según datos del - SRI, Servicio de Rentas Internas-, los impuestos recaudados ascendieron a USD 7535 millones, de los cuales un 44,4\% correspondían al IVA, 5,9\% impuesto de consumos especiales (ICE), 30,6\% por impuesto a la renta, $11,5 \%$ por aranceles y el restante $7,6 \%$ a «otros».

36 Conocemos el elemento básico de la Ley de Gresham, vigente cuando en un país circulan simultáneamente dos - o más - tipos de moneda del mismo valor nominal, y una de ellas es considerada por los usuarios como «buena» - por su mayor valor intrínseco-y la otra como «mala», ésta termina por expulsar del mercado a la buena.

37 Sobre el papel que cumpliría el sector financiero privado cuando el sistema bimonetario esté consolidado habría que pensar más a fondo para impedir que la banca llegue a controlar la emisión del EC\$.

38 Los autores de este texto han discutido conjuntamente el tema de la inflación y también esta crucial cuestión de la hiperinflación, que ha sido en varias épocas un azote para las economías de la región véase Schuldt y Acosta, 1995-.

39 El encaje de la banca estatal y de las demás instituciones financieras - cooperativas de ahorro, asociaciones autogestionarias, mutualistas y demás - no se verían afectadas por este incremento del encaje, en especial porque favorecemos la expansión de la inclusión financiera de las micro y pequeñas empresas, así como de otras asociaciones de crédito solidario.

40 En su forma más sencilla el «multiplicador monetario» (m) es igual a la inversa de la tasa de encaje (e): $m=1 / e$. Lo que, en el caso de Ecuador, con un encaje del $5 \%$ significaría que el multiplicador es de 20, ceteris paribus — es decir, dada la preferencia por liquidez-.

41 Aquí también se podría considerar el manejo controlado de las tasas de interés como sugiere el enfoque del dinero endógeno, siempre y cuando sea aplicable para el caso ecuatoriano.

42 El вCE no tiene una medición real del circulante en dólares. Eso podría ser un problema pues, al menos por ahora, no hay las herramientas que permitan medir realmente hasta qué punto el EC\$ reemplazaría al us\$ en términos de circulante — solo podemos hacer eso en términos de depósitos-. 
43 Las variaciones de la Reserva Monetaria Internacional Neta — netas del encaje bancario- provienen de la balanza comercial — diferencia entre las exportaciones e importaciones de bienes-, de la balanza de servicios - remisión de utilidades netas al extranjero, transportes, pago de intereses sobre la deuda externa - y de la balanza de capitales -inversión extranjera directa neta, servicio neto del capital sobre la deuda externa, flujos de capital de corto plazo y demás-.

44 Un grupo de autores del Levy Economics Institute ha elaborado una propuesta de dinero paralelo -inspirados en el sistema suizo del WIR - para los países de la eurozona en crisis. Véanse los textos de D. Papadimitriou et al. (2016 a y 2016b).

45 No se trata de cualquier crecimiento. Es al menos oportuno diferenciar el crecimiento «bueno» del «malo»; crecimiento que - haciendo referencia a la carta abierta de Manfred Max-Neef (2011) al presidente de Chile - se define por sus correspondientes historias naturales y sociales, tanto como por el futuro que este crecimiento pueda anticipar.

46 Es decir, a diferencia de décadas previas en que las metas monetarias les servían de guía a los bancos centrales para monitorear y controlar la inflación, ahora la mayoría de ellos aplica el principio de metas inflacionarias en base a la regla de Taylor. Ésta sirve para determinar la tasa de interés de referencia - que sirve de guía para el ajuste de tasas de interés del sistema financiero-, según la evolución de la inflación y el PIB. Así, la tasa de referencia la aumenta el directorio del banco central cuando la inflación efectiva se acerca o rebasa la inflación meta y/o cuando el PIB efectivo se acerca o rebasa al PIB potencial de la economía. Se reduce la tasa de referencia si sucede lo contrario. En ambos casos también se toma en cuenta la tasa de interés internacional de largo plazo. Además, aunque no forma parte de la regla de Taylor, en la práctica los bancos centrales también consideran la evolución del tipo de cambio e intervienen en el mercado de divisas para evitar su volatilidad.

47 Dado que el gobierno tendría que enfrentar tanto una dinámica monetaria exógena como endógena, quizá sería interesante empezar a proponer «metas mixtas», es decir, metas que se enfoquen en inflación, pero que también consideren la regulación del manejo de masa monetaria en los casos de emisión de dinero físico. 48 Ciertamente el «argumento» central de quienes se opondrán a nuestra propuesta — no solo aquellos economistas neoliberales defensores de la dolarización- es que en el Ecuador es imposible tener un banco central con un directorio autónomo o siquiera relativamente independiente; la experiencia vivida abona en esta dirección: recuérdese como la Junta Monetaria estaba controlada por la banca privada. Sin embargo, insistimos en este tema.

49 Habrá que prever las medidas adecuadas que impidan que los sectores oligopólicos no financieros, que participen en el sistema, aparte de volverse especuladores, empiecen a actuar como financieros: otorgar créditos en EC\$, jugando con el plazo de los dos años y la paridad asegurada.

50 Nótese que la propuesta aquí sintetizada es solo una de las múltiples variantes para establecer una moneda «complementaria», si bien consideramos que es la que mejor se aplica a las peculiaridades de la economía ecuatoriana. Ciertamente, este complejo tema abarca asimismo aspectos básicos de corte social, político, legal e institucional que aquí no hemos tratado a profundidad por limitaciones de espacio y de capacidad de los autores. Abrigamos la esperanza que los estudiantes de la actual generación - teniendo en cuenta que las anteriores se han resignado a la dominante ortodoxia económica- se aboquen al estudio de estas propuestas heterodoxas que no solo son un desafío teórico-político, sino que pueden contribuir a aliviar los tremendos costos sociales que implican los programas ortodoxos de ajuste y estabilización que amenazan aplicarse - a falta de creatividad y por intereses particulares del poder establecido- en los próximos años en el país.

51 Ésta es otra cuestión que los dos autores han trabajado, inclusive de forma conjunta: Schuldt (2005), Schuldt y Acosta (2006), Acosta (2009), Acosta y Cajas Guijarro (2016b).

52 El texto de síntesis que aquí presentamos recoge casi textualmente lo presentado por los autores en su «Manifiesto» (Bossone et al., 2015; ver también: Bossone y Cattaneo, 2015).

53 Paralelamente a estos certificados, que servirían para remontar la «trampa de la liquidez», los autores sugieren adicionalmente - para los países altamente endeudados - la emisión de «bonos respaldados en impuestos» para afrontar la «trampa de la deuda». Ya que el Ecuador tiene una deuda que se acerca al 
tope del 40\% del PIB establecido por ley -60\% es el límite en la Unión Europea-, este componente del plan no la detallaremos aquí por innecesaria.

\section{REFERENCIAS}

Acosta, A. (1994). Los nombres de la deuda. Sucretizadores, canjeadores y tenedores. Quito, Ecuador: CAAP, FONDAD.

Acosta, A. (2004). Dolarización o desdolarización, ¡ésa no es toda la cuestión! Íconos, (19), 54-65.

Acosta, A. (2009). La maldición de la abundancia. Quito, Ecuador: CEP, Swissaid y Abya-Yala.

Acosta, A. (2012). Breve historia económica del Ecuador. Quito, Ecuador: Corporación Editora Nacional. Acosta, A. et al. (2013a). El país que queríamos. Quito, Ecuador: Montecristi Vive.

Acosta, A. (2013b). El Buen Vivir. Sumak Kawsay, una oportunidad para imaginar otros mundos. Barcelona, España: Icaria Editorial.

Acosta, A. y Schuldt, J. (200o). ¿Dolarización: vacuna para la hiperinflación? Ecuador Debate, (49). Recuperado de http://repositorio.flacsoandes.edu.ec/handle/10469/5613\#.wADI5fnhBdg

Acosta, A. y Schuldt, J. (2006). Petróleo, rentismo y subdesarrollo: ¿Una maldición sin solución? Nueva Sociedad. Recuperado de http://nuso.org/articulo/petroleo-rentismo-y-subdesarrollo-unamaldicion-sin-solucion/

Acosta, A. y Cajas Guijarro, J. (2015). La herencia económica del correísmo. Plan v. Recuperado de http:// www.planv.com.ec/investigacion/investigacion/la-herencia-economica-del-correismo

Acosta, A. y Cajas Guijarro, J. (2016a). Ocaso y muerte de una revolución que al parecer nunca nació. Democracia Sur. Recuperado de http://democraciasur.com/2016/og/10/ecuador-ocasoy-muerte-de-una-revolucion-que-al-parecer-nunca-nacio/

Acosta, Alberto y Cajas Guijarro, John (2016b). Patologías de la abundancia. Una lectura desde el extractivismo. En H. J. Burchardt, R. Domínguez, C. Larrea y S. Peters (Eds.), Nada dura para siempre Neo-extractivismo tras el boom de las materias primas (pp. 391-425). Quito: Universidad Andina Simón Bolívar. Kassel: Universität Kassel. Recuperado de http://www.burchardt.uni-kassel.de/ wp-content/uploads/2016/o9/Nada-dura-para-siempre-15_septiembre_2016.pdf

Andresen, T. (2015). Syriza, you can do this-and you can do it now. Real-world economics review blog. Recuperado de https://rwer.wordpress.com/2015/o8/10/syriza-you-can-do-thisand-you-can-do-it-now/

Andresen, T. y Parenteau, R. W. (2015a). A program proposal for creating a complementary currency in Greece. Real-world economics review, (71), 2-10. Recuperado de www.paecon.net/paEReview/ issue71/whole71. pdf

Andresen, T. y Parenteau, R. W. (2015b). A detailed program proposal for creating a parallel currency in Greece. Real-world economics review blog. Recuperado de https://rwer.wordpress. com/2015/03/28/a-detailed-program-proposal-for-creating-a-parallel-currency-in-greece/

Bossone, B., Cattaneo, M., Gallino, L., Grazzini, E., and Sylos Labini, S. (2015). Free fiscal money: exiting austerity without breaking up the euro. Associazione Paolo Sylos Labini. Recuperado de http:// www.syloslabini. info/online/wp-content/uploads/2014/11/Appello-Inglese-rivisto_9-03-2015.pdf

Bossone, B. and Cattaneo, M. (2015). A parallel currency for Greece (parts I, II). VoxEU.org. Recuperado de www. voxeu.org/article/parallel-currency-greece-part-i; www.voxeu.org/article/parallel-currencygreece-part-ii 
Correa, R. (2005). Dolarización y políticas alternativas. Revista del Sur. (s. p.) Recuperado de http://old. redtercer mundo.org.uy/revista_del_sur/texto_completo.php?id=2816

Friedman, M. (1969). The optimum quantity of money. En M. Friedman, The Optimum Quantity of Money and Other Essays (pp. 1-50), Chicago, usa: Adline Publishing.

Gesell, S. ([1916] 1936). El orden económico natural por libretierra y libremoneda. Buenos Aires, Argentina: E. F. Gesell.

Greco, T. (1994). New money for healthy communities. Arizona, UsA: Greco Pub.

Harvey, A. (2015). Updated proposal for a complementary currency for Greece (with response to critics). Real-world economics review, (71), 11-18. Recuperado de www.paecon.net/PAEReview/issue71/ Harvey71.pdf

Hayek, F. (1986). Desnacionalización de la moneda. Barcelona, España: Instituto de Economía de Mercado.

Heise, M. (2015). The real tragedy of the Greek crisis. World Economic Forum. Recuperado de https:// agenda. weforum.org/2015/o6/what-has-gone-wrong-in-the-greek-debate/

Hilliger, C. (2015). From TREXIT to GREXIT? - Quo vadis hellas? Real-world economics review, (70), 161163. Recuperado de www.paecon.net/PAEReview/issue7o/Hillinger7o.pdf

Honzawa Puig, A. y Torrens, L. (2015a). La tercería vía para Grecia: del Grexit al Greuro. Sin Permiso. (s. p.) Recuperado de www.sinpermiso.info/textos/index.php?id=7743

Honzawa Puig, A. y Torrens, L. (2015b). Grecia y el Greuro: ¿Hay vida después de la muerte? Sin Permiso. (s. p.) Recuperado de www.sinpermiso.info/articulos/ficheros/11greuro.pdf

Karatsoris, N. (2015). A complementary currency for Greece. Recuperado de http://folk.ntnu.no/tronda/ econ/ Currency-Greece-Karatsoris.pdf

Kennedy, M., Lietaer B. and Rogers, J. (2012). People Money. The promise of regional currencies. Triarchy Press. Recuperado de www.triarchypress.net/people-money.html\#sthash.bKaXnMxZ.dpuf

Lietaer, B. (2015). No reason why Greece could not have two currencies'. A euro architect. RTQuestion More. Recuperado de www.rt.com/op-edge/271504-greece-euro-drachma-economy/; www.youtube.com/watch? v=INGJvyep6zo.

Lietaer, B. (2012). Press Release: 'Geuro'. A parallel currency for Greece is not a new idea. Money Sustainability. Recuperado de www.money-sustainability.net/press-release-geuro-a-parallelcurrency-for-greece-is-not-a-new-idea/

Lo Vuolo, R. (2001). Alternativas. La economía como cuestión social. Buenos Aires, Argentina: Grupo Editorial Altamira.

Max-Neef, M. (2011). Carta abierta al Presidente Piñera. Recuperado de http://www.chw.net/foro/ actualidad/894884-carta-abierta-manfred-max-neef-sebastian-pinera.html

Mayer, T. (2015a). A parallel currency for Greece. Centre for European Policy Studies. Recuperado de www. ceps.eu/system/files/No4_TM\%2oParallel\%2oCurrency_o.pdf

Mayer, T. (2015b). A parallel currency for Greece. Economic policy note Flossbach von Storch Research Institute. Recuperado de www.fvs-ri.com/files/parallel_currency_for_greece.pdf

MoU (2015). Memorandum of understanding between the European Commission acting on behalf of the European Stability Mechanism and the Hellenic Republic and the Bank of Greece. Recuperado de http://ec. europa.eu/economy_finance/assistance_eu_ms/greek_loan_facility/ pdf/o1_mou_20150811_en.pdf.

Papadimitriou, D., Nikiforos, B. M. and Zezza, G. (2016a). How long before growth and employment 
are restored in Greece? Strategic Analysis. Recuperado de http://www.levyinstitute.org/pubs/ sa_gr_1_16.pdf

Papadimitriou, D. Nikiforos, B. M. and Zezza, G. (2016b). A complementary currency and direct job creation hold the key to Greek recovery. One-Pager, (52), (s. p.). Recuperado de http://www.levyinstitute.org/pubs/ op_52.pdf

Parenteau, R. (2015). Robert Parenteau: Get a TAN, Yanis: A Timely Alternative Financing Instrument for Greece. Naked Capitalism. Recuperado de www.nakedcapitalism.com/2015/o2/robert-parenteauget-tan-yanis-timely-alternative-financing-instrument-greece.html

Parenteau, R. (2013). How to Exit Austerity, Without Exiting the Euro. New Economic Perspectives. Recuperado de http://neweconomicperspectives.org/2013/12/exit-austerity-without-exiting-euro.html

Piketty, T. (2015). Germany has never repaid its debts. It has no right to lecture Greece. The Wire. Recuperado de http://thewire.in/2015/07/o8/thomas-piketty-germany-has-never-repaid-itsdebts-it-has-no-right-to-lecture-gree ce-5851/

Rogers, J. (2015). Currency is destiny: New currencies for new times. World Economics Association Newsletter, 5(4), 3-4. Recuperado de www.worldeconomicsassociation.org/files/Issue5-4.pdf.

Rogers, J. (2013). Local money what difference does it make? Triarchy Press. Recuperado de www.triarchypress. net/local-money.html\#sthash.7pyjhhRj.dpuf

Rogoff, K. (2016). The curse of cash. Princeton and Oxford, USA: Princeton University Press.

Sapir, J. (2015). Could a parallel currency have saved Greece? Varoufakis' plan «B», parallel currencies, and the Euro. Carnets de recherche. Recuperado de https://russeurope.hypotheses.org/4589

Schuldt, J. (1997). Dineros alternativos para el desarrollo local. Lima, Perú: Centro de Investigación de la Universidad del Pacífico.

Schuldt, J. (1999). Dolarización oficial de la economía: un debate en once actos. Serie «Apuntes de Estudio», (36). Lima, Perú: Centro de Investigación de la Universidad del Pacífico.

Schuldt, J. (2005). Somos pobres porque somos ricos. Recursos naturales, tecnología y globalización. Lima, Perú: Fondo Editorial del Congreso del Perú.

Schuldt, J. (2011). Transforndo estructural y sociopolítico de la crisis estadounidense. Visión panorámica y perspectivas. Lima, Perú: Centro de Investigación, Universidad del Pacífico.

Schuldt, J. (2013). Desarrollo a escala humana y de la naturaleza. Lima, Perú: Centro de Investigación de la Universidad del Pacífico.

Schuldt, J. y Acosta, A. (1995). Inflación: enfoques y políticas alternativas para América Latina y el Ecuador. Quito, Ecuador: LIBRESA e ILDIS.

Schuldt, J. y Acosta, A. (1999). La hora de la reactivación: el mito de la falta de alternativas. Serie Dialogando con los líderes ecuatorianos. Guayaquil, Ecuador: Escuela Politécnica del Litoral.

Schuster, L. (2013). Parallel currencies for the Eurozone. An outline and an attempt at systematisation. Veblen Institute for Economic Reforms. Recuperado de www.veblen-institute.org/IMG/pdf/schuster_parallel_currencies_for_the_eurozone_final.pdf

Von dem Berge, L. (2014). Parallel currencies in historical perspective. CAWm Discussion Paper, (75), (s. p.). Recuperado de https://www.econstor.eu/bitstream/10419/103731/1/802547729.pdf

Varoufakis, Y. (2013). Bitcoin and the dangerous fantasy of 'apolitical' money'. Yanisvaroufakis.eu. Recuperado de http://yanisvaroufakis.eu/2013/04/22/bitcoin-and-the-dangerous-fantasy -of-apolitical-money/ 
Varoufakis, Y. (2014, febrero 15). Bitcoin: A flawed currency blueprint with a potentially useful application for the Eurozone. Yanis Varoufakis. Recuperado de http://yanisvaroufakis.eu/2014/o2/15/ bitcoin-a-flawed-currency-blueprint-with-a-potentially-useful-application-for-the-eurozone/

Varoufakis, Y. (2015). Un nuevo acuerdo para Grecia. Project Syndicate. Recuperado de www.project-syndicate.org/commentary/greece-debt-deal-by-yanis-varoufakis-2015-04/spanish 